\title{
Representation of climate extreme indices in the ACCESS1.3b coupled atmosphere-land surface model
}

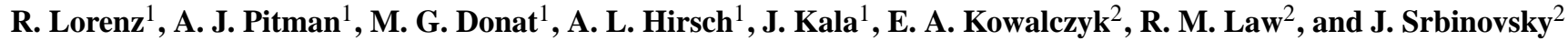 \\ ${ }^{1}$ ARC Centre of Excellence for Climate System Science and Climate Change Research Centre, \\ University of New South Wales, Australia \\ ${ }^{2}$ Centre for Australian Weather and Climate Research, CSIRO Marine and Atmospheric Research, Australia
}

Correspondence to: R. Lorenz (r.lorenz@unsw.edu.au)

Received: 21 October 2013 - Published in Geosci. Model Dev. Discuss.: 3 December 2013

Revised: 12 February 2014 - Accepted: 19 February 2014 - Published: 4 April 2014

\begin{abstract}
Climate extremes, such as heat waves and heavy precipitation events, have large impacts on ecosystems and societies. Climate models provide useful tools for studying underlying processes and amplifying effects associated with extremes. The Australian Community Climate and Earth System Simulator (ACCESS) has recently been coupled to the Community Atmosphere Biosphere Land Exchange (CABLE) model. We examine how this model represents climate extremes derived by the Expert Team on Climate Change Detection and Indices (ETCCDI) and compare them to observational data sets using the AMIP framework. We find that the patterns of extreme indices are generally well represented. Indices based on percentiles are particularly well represented and capture the trends over the last 60 years shown by the observations remarkably well. The diurnal temperature range is underestimated, minimum temperatures $\left(T_{\mathrm{MIN}}\right)$ during nights are generally too warm and daily maximum temperatures ( $T_{\text {MAX }}$ ) too low in the model. The number of consecutive wet days is overestimated, while consecutive dry days are underestimated. The maximum consecutive 1-day precipitation amount is underestimated on the global scale. Biases in $T_{\text {MIN }}$ correlate well with biases in incoming longwave radiation, suggesting a relationship with biases in cloud cover. Biases in $T_{\text {MAX }}$ depend on biases in net shortwave radiation as well as evapotranspiration. The regions and season where the bias in evapotranspiration plays a role for the $T_{\text {MAX }}$ bias correspond to regions and seasons where soil moisture availability is limited. Our analysis provides the foundation for future experiments that will examine how land-surface processes contribute to these systematic biases in the ACCESS modelling system.
\end{abstract}

\section{Introduction}

Climate extremes, including heat waves, heavy precipitation events or droughts have important effects on ecosystems and society (Easterling, 2000; Ciais et al., 2005; Pall et al., 2011). Many climate extremes are related to natural variability (Arblaster and Alexander, 2012; Seneviratne et al., 2012). However, climate change has the ability to modify the frequency, intensity, spatial extent, duration, and timing of climate extremes, and can lead to events unprecedented in the historical record (Seneviratne et al., 2012). Given the impact of extremes, it is important to understand their causes, how they might change in the future and the role of potential interacting processes and feedbacks that might amplify them. This is urgent given that some extremes appear to be increasing in frequency (Alexander et al., 2006; Coumou and Rahmstorf, 2012; Donat and Alexander, 2012; Perkins et al., 2012) and that extremes are considered to be a particularly challenging aspect of climate change adaptation (IPCC, 2012).

Extreme events can be directly influenced by land-surface processes. Heat waves for example can be amplified by landsurface processes including dryness and decreased vegetation (Zaitchik et al., 2006; Fischer et al., 2007; Koster et al., 2009; Hirschi et al., 2010; Stéfanon et al., 2012; Lorenz et al., 2013). Limited soil moisture availability and less active vegetation decreases evapotranspiration and, therefore, more energy is available for the sensible heat flux which increases temperatures (e.g. Seneviratne et al., 2010). Temperature variability is also affected by land-surface processes (Seneviratne et al., 2006) and Jaeger and Seneviratne (2010) found a tendency towards a greater impact of land-surface 
processes on maximum temperatures, as distinct from minimum temperatures. The land-atmosphere coupling mechanisms for maximum and minimum temperatures differ. A clear relationship between maximum temperature and realistic soil moisture initialisation was found by Hirsch et al. (2014). This is in contrast to minimum temperatures where the influence of soil moisture is less clear given the role of net longwave emission in modulating nighttime temperatures. Interactions between the land surface and precipitation also exist, but the scale of the impact is less clear. It remains uncertain how soil moisture affects rainfall, with no agreement on the sign of the feedback (Findell and Eltahir, 2003; Ek and Holtslag, 2004; Taylor and Ellis, 2006). Pitman et al. (2012) analysed several global climate models to examine the impact of land-use changes on temperature and precipitation extremes and found opposing effects to the impact of increasing $\mathrm{CO}_{2}$ for some extreme indices and additive impacts for others. In short, to understand the changes in extremes linked with natural variability or increasing $\mathrm{CO}_{2}$ we need to understand how land-surface processes influence climate extremes.

Land-atmosphere feedbacks are difficult to investigate using observations alone because of the lack of suitable longterm data sets and the uncertainty regarding how feedbacks might change in the future with climate change. Climate models are useful tools for investigating land-atmosphere feedbacks and their influence on extreme events (Fischer et al., 2007; Jaeger and Seneviratne, 2010; Lorenz et al., 2010). In Australia, a new global earth system model (ACCESS) has been developed (Bi et al., 2013; Kowalczyk et al., 2013). ACCESS1.0 compares well with other models in the Coupled Model Intercomparison Project, version 5 (CMIP5) with regards to the representation of extremes (Sillmann et al., 2013). A more recent version of the model, ACCESS1.3, has also been used to run CMIP-5 simulations and performs similarly to ACCESS1.0 (Kowalczyk et al., 2013). Two major differences between ACCESS1.0 and ACCESS1.3 are the parameterisation of the land surface and the cloud scheme. In ACCESS 1.0, the UK Meteorological Office Surface Exchange Scheme (MOSES) is used, but is replaced in ACCESS1.3 by the Community Atmosphere Biosphere Land Exchange (CABLE1.8) model. The two versions of the model were compared by Kowalczyk et al. (2013), although this analysis did not examine the representation of extreme events.

In this study, we undertake an analysis of the ACCESS1.3 model in terms of its ability to simulate a selection of extremes. We use ACCESS1.3, but replace CABLE1.8 with CABLE2.0 (the most recent released version) in an overall modelling system labelled ACCESS1.3b. We use an Atmospheric Model Intercomparison Project (AMIP) style experimental design (Gates, 1992) involving simulations over the 1950-2012 period with prescribed sea surface temperatures and sea ice concentration. The use of the AMIP experimental design decreases the uncertainty in terms of sea surface temperatures and associated teleconnections including the El Niño-Southern Oscillation. Our analysis focuses on the simulation of climate extreme indices defined by the Expert Team on Climate Change Detection and Indices (ETCCDI) which are provided by two observational data sets by Donat et al. (2013a, b). Our goal is to assess the skill of ACCESS1.3b in simulating extremes and to identify systematic biases, strengths and weaknesses. This provides us with the foundation for future experiments aimed at resolving deficiencies, particularly where these relate to land-surface processes. This study is organised as follows: Sect. 2 gives an overview of the model used and the data sets we used for evaluation. Section 3 provides our results. Section 4 provides a discussion and finally Sect. 5 concludes our study.

\section{Data and method}

\subsection{Australian Community Climate and Earth System Simulator (ACCESS1.3b)}

The Australian Community Climate and Earth System Simulator (ACCESS) has been developed at the Centre for Australian Weather and Climate Research (CAWCR) to provide the Australian climate community with a state-of-theart fully coupled climate model as well as weather prediction model (Puri et al., 2013). ACCESS1.3b consists of the atmospheric Unified Model (UM7.3, UK Meteorological Office), the Community Atmosphere Biosphere Land Exchange land surface model (CABLE2.0, CSIRO), the Modular Ocean Model (NOAA/GFDL), the Los Alamos sea ice model CICE (LANL) and the coupling framework OASIS (CERFACS) which couples the ocean and sea ice to the atmosphere (Bi et al., 2013). We use ACCESS1.3b in an AMIP-style configuration with prescribed sea surface temperatures and sea ice fractions. These were sourced from the Program for Climate Model Diagnosis and Comparison (Taylor et al. (2000), http://www-pcmdi.llnl.gov/projects/ amip/AMIP2EXPDSN/BCS/amipbc_dwnld.php) and regridded and converted to the UM's data format at the UK Meteorological Office. We performed simulations at $1.25^{\circ}$ latitude $\times 1.875^{\circ}$ longitude resolution (N96 resolution), 38 vertical levels, and a $30 \mathrm{~min}$ time step. The simulation covers the 1950-2012 period, the first year is used as a spin-up period and not included in the analysis. Orography in ACCESS1.3b is derived from the 30" GLOBE data set (GLOBE Task Team and others, 1999). However, since this data set has deficiencies over Australia (Bi et al., 2013), it is improved for the Australian region using the Geoscience Australia highquality data set (Hilton et al., 2003).

\subsubsection{The atmosphere: Unified Model (HadGEM3)}

The atmospheric model in ACCESS1.3b is the Unified Model developed at the UK Meteorological Office (Davies et al., 2005; Martin et al., 2006). Atmospheric dynamics 
in the UM are non-hydrostatic, fully compressible and the advection scheme is semi-Lagrangian. The vertical coordinates are height based and follow the terrain, and a regular Arakawa $\mathrm{C}$ grid is used in the horizontal. The radiation scheme is a general two-stream scheme developed by Edwards and Slingo (1996), but was improved in terms of pressure and temperature scaling. In addition, the tripleclouds scheme of Shonk and Hogan (2008) was included to improve the representation of horizontal cloud inhomogeneity. Calculation of the radiation scheme is performed eight times per day (3-hourly). Convection is parameterised by a modified mass flux scheme based on Gregory and Rowntree (1990). The boundary layer mixing scheme represents nonlocal mixing in unstable layers and an explicit entrainment parameterisation (Lock et al., 2000). The cloud microphysics scheme contains water vapour, total cloud fraction, cloud liquid water and cloud ice as prognostic variables and we use the PC2 prognostic condensate scheme described in Wilson et al. (2008). Atmospheric chemistry includes the aerosol sulfate, soot, biomass, dust (from IGBP soils, although values are very low), sea salt, and biogenic (climatology only) aerosols. Aerosol emissions are prescribed by monthly climatologies, and aerosols can be advected and deposited. More details can be found in Hewitt et al. (2011) and Bi et al. (2013).

\subsubsection{The land surface: Community Atmosphere Biosphere Land Exchange (CABLE2.0)}

Land-surface models simulate biogeophysical and biogeochemical processes and handle the exchange of surface fluxes between the land surface and the atmosphere. Since the extremes explored in this paper are intimately associated with how the land surface is parameterised we provide some detail on how CABLE represents terrestrial processes. Further detailed descriptions of CABLE1.4 can be found in Wang et al. (2011) and CABLE1.8 in Kowalczyk et al. (2013).

CABLE consists of three submodels: (1) canopy processes, (2) soil and snow, and (3) carbon pool dynamics and soil respiration. Canopy processes are simulated by a onelayer two-leaf canopy scheme, distinguishing between sunlit and shaded leaves for the calculation of photosynthesis, stomatal conductance and leaf temperature (Wang and Leuning, 1998). The vegetation is placed above the ground, which allows for aerodynamic and radiative interactions between the ground and the canopy. CABLE includes a sub-grid tiling approach at the surface, meaning that several surface types can exist within a grid cell (ten vegetation types and three non-vegetated types are distinguished; up to five tiles can be used within each grid cell). The soil model has six layers and the Richards equation is solved for soil moisture, while soil temperature is calculated from the heat conduction equation. The snow model has three snowpack layers and calculates the temperature, density and thickness of the snow. The carbon pool model used is simple, and net primary productivity is calculated from the annual carbon assimilation corrected for respiratory losses (carbon fluxes are not assessed in this study). The differences between CABLE1.8 used in Kowalczyk et al. (2013) and CABLE2.0 used here are small. They include bug fixes and updated optical leaf properties (transmission and reflectance) that are better calibrated for the snow-free soil albedo used by ACCESS.

CABLE has been extensively evaluated (Abramowitz et al., 2008; Wang et al., 2011) and an earlier version was used in the Land Use Change IDentification of robust impacts (LUCID) project (Pitman et al., 2009; de NobletDucoudré et al., 2012). Furthermore, Mao et al. (2011) documents the performance of a low-resolution GCM of intermediate complexity, CSIRO Mk3L, coupled to an earlier version of CABLE (version 1.4b) with a focus on terrestrial quantities. This analysis provides strong evidence that the coupled model produces a reasonable large-scale climatology. More recently, Zhang et al. (2013) ran CABLE2.0 offline with GSWP2 (Global Soil Wetness Project) forcing and compared it with other participating land-surface models in GSWP and gridded observations. They found that whilst global mean evapotranspiration (ET) simulated by CABLE agreed well with other land-surface models and observations, CABLE underestimated ET in the tropics and had significant runoff errors. In addition, CABLE showed a large sensitivity to soil and vegetation parameters in tropical rainforests and mid-latitude forest regions.

\subsection{ETCCDI indices and data sets}

The Expert Team on Climate Change Detection and Indices (ETCCDI) defined a set of 27 indices calculated from daily maximum $\left(T_{\mathrm{MAX}}\right)$ and minimum $\left(T_{\mathrm{MIN}}\right)$ temperatures and daily precipitation (http://www.climdex.org/ indices.html). These indices were developed to investigate changes in intensity, duration and frequency of extreme climate events. Most of these indices describe moderate extremes with return periods of a year or shorter. We calculate all indices using freely available software (http:// www.climdex.org/climdex_software.html) and compare the indices from our simulations to the HadEX2 data set (Donat et al., 2013b). Only a subset of the indices is analysed in detail (see Table 1). We chose four indices that examine the frequency of high (warm days TX90p, warm nights TN90p) and low (cool days TX10p, cool nights TN10p) temperature extremes, and one temperature index investigates the amplitude between the coldest and hottest temperature per day (diurnal temperature range DTR). Two of the chosen indices examine wet precipitation extremes (maximum 1-day precipitation amount Rx1day, consecutive wet days CWD) and one index looks at dryness (consecutive dry days CDD). For temperature extremes, we chose mainly indices based on percentiles which are relative to the base period 1961-1990 because they are applicable over all climate zones and show robust trends in observational data sets (Zhang et al., 2011; Donat et al., 2013b). The precipitation indices were chosen to examine 
several aspects of precipitation extremes, high precipitation amounts in Rx1day, high precipitation frequency in CWD and low precipitation frequency and drought in CDD.

\subsubsection{HadEX2 data set}

The HadEX2 data set, described in detail by Donat et al. (2013b), contains 17 temperature and 12 precipitation indices. These are derived from daily maximum and minimum temperature and precipitation observations for the period covering 1901 to 2010. The indices were calculated for each station and then the monthly and annual indices were interpolated onto a $2.5^{\circ}$ latitude $\times 3.75^{\circ}$ longitude grid. Donat et al. (2013b) derived linear trends from the gridded fields and tested these trends for statistical significance. The highquality in situ observations were primarily sourced from the European Climate Assessment and Data set (ECA\&D) and associated data sets in southeast Asia and Latin America, GHCN-Daily (USA-only), ETCCDI regional workshops and individual researchers. As a result, the spatial availability of HadEX2 data varies with time. Trend estimates can be influenced by the number of stations included in a data set. To compare time series and trends of model and observations we calculated global averages. We apply a time independent masking of the model data and HadEX2, only including grid points where more than 50 years of observational data (out of 60) are available. This minimises the deteriorating effect of variable spatial coverage on the trend calculations. The spatial coverage of the Rxlday index is larger in monthly than annual fields because the decorrelation length scale is larger for monthly compared to yearly extreme precipitation indices. To obtain a spatial coverage that is as good as possible, we calculate the annual maximum Rx1day amounts from the maximum of the monthly Rx1day fields provided by HadEX2. This increases data availability in data sparse regions (e.g. tropics); however, it needs to be taken into account that this may include stations which are less representative of a certain grid point. Therefore, grid points around areas with missing data need to be interpreted with care.

When comparing models and gridded observational data sets for extremes, it needs to be kept in mind that scaling effects likely play a role. That is, the gridded observational data set is derived from annual extremes at each station, whereas the models represent a grid-point average for each day. Therefore, annual maxima from climate models are expected to be lower in intensity, especially for precipitationbased indices (Kiktev et al., 2003; Tebaldi et al., 2006).

\subsubsection{Other data sets}

We use the HadGHCND gridded daily temperature data set (Caesar et al., 2006) derived from near-surface maximum and minimum temperature observations. It covers the period from 1951 to the present on a $2.75^{\circ}$ latitude $\times 3.75^{\circ}$ longitude grid. It was designed for the analysis of climate extremes and the evaluation of climate models. Note that the data coverage varies with time.

We also use the Global Precipitation Climatology Project (GPCP) Version-2 precipitation (http://www.esrl.noaa.gov/ $\mathrm{psd} / \mathrm{data} /$ gridded/data.gpcp.html) data set. This is derived from a combination of satellite and rain-gauge measurements (Adler et al., 2003). GPCP is available as a global, monthly analysis of surface precipitation at $2.5^{\circ} \times 2.5^{\circ}$ resolution from 1979 to the present (we use December 1979-November 2012 here). GPCP has been shown to agree well with groundbased observations (Ma et al., 2009; Pfeifroth et al., 2013).

The NASA "Clouds and the Earth's Radiant Energy System" (CERES EBAF Surface Ed2.7) data set provides satellite-based estimates of surface radiative fluxes. This data set was specifically created for evaluation of climate models (http://ceres-tool.larc.nasa.gov). It includes surface downwelling shortwave and longwave radiation, surface upwelling shortwave and longwave radiation and estimates for clearsky radiation from 2001 to 2009 . Kato et al. (2013) found that the biases over land were, on average, $21.7 \mathrm{~W} \mathrm{~m}^{-2}$ for downward shortwave and $21.0 \mathrm{~W} \mathrm{~m}^{-2}$ for downward longwave radiation. Therefore, biases between $\pm 10 \mathrm{~W} \mathrm{~m}^{-2}$ are not taken into account in our analysis.

For evapotranspiration, we use the GLEAM (Global Landsurface Evaporation: the Amsterdam Methodology, Miralles et al. (2011)) global evapotranspiration data set and the LandFlux-EVAL data set (Mueller et al., 2013). GLEAM is derived from various satellite products within a PriestleyTaylor framework (Priestley and Taylor, 1972). It estimates daily evaporation at a global scale and a $0.25^{\circ}$ spatial resolution and is available from 1984 to 2007. GLEAM uses microwave-derived soil moisture, land-surface temperature and vegetation density, as well as the detailed estimation of rainfall interception loss. GLEAM has been found to have a low average bias ( $<5 \%$, Miralles et al., 2011). LandFluxEVAL is a merged multi-data benchmark product. It contains data from different sources including satellites, in situ observations, land-surface models and reanalysis. We use the longer period data product (1989-2005) where 14 different data sets, including GLEAM, were used.

Given the sparse coverage and limited availability of flux observations, satellite estimates provide the "next-best approximation". Although these are strictly models, and not true observations, the algorithms are usually constrained by as much data as possible (e.g. the GLEAM ET product is driven with gridded precipitation observations), and hence, these products have a well-defined accuracy and are, therefore, useful for comparing against global climate models (GCMs), which have much larger degrees of freedom. For the calculation of the biases we used the coarsest grid involved, either interpolating the model output to the coarser grid of the observational data set or interpolating the observations to the model resolution. Table 2 summarises the data sets used for evaluation. 
Table 1. Extreme temperature and precipitation indices used in this study. The first four indices measure frequency of temperature extremes, DTR measures the amplitude between the coldest and hottest daily temperatures and the last four indices measure rainfall extremes (three wet extremes, last one dry extreme). Percentiles are calculated over the 1961-1990 reference period.

\begin{tabular}{|c|c|c|c|}
\hline Index & Indicator Name & Definition & Unit \\
\hline TX10p & Cool days & $\begin{array}{l}\text { Percentage of time when daily max. } \\
\text { temperature }<10 \text { th percentile }\end{array}$ & $\%$ \\
\hline TN10p & Cool nights & $\begin{array}{l}\text { Percentage of time when daily min. } \\
\text { temperature }<10 \text { th percentile }\end{array}$ & $\%$ \\
\hline TX90p & Warm days & $\begin{array}{l}\text { Percentage of time when daily max. } \\
\text { temperature }>90 \text { th percentile }\end{array}$ & $\%$ \\
\hline TN90p & Warm nights & $\begin{array}{l}\text { Percentage of time when daily min } \\
\text { temperature }>90 \text { th percentile }\end{array}$ & $\%$ \\
\hline DTR & Diurnal temperature range & $\begin{array}{l}\text { Annual mean difference between } \\
\text { daily max. and min. temperature }\end{array}$ & ${ }^{\circ} \mathrm{C}$ \\
\hline Rx1day & Max. 1-day precipitation & $\begin{array}{l}\text { Annual maximum consecutive } \\
\text { 1-day precipitation amount }\end{array}$ & $\mathrm{mm}$ \\
\hline Rx5day & Max. 5-day precipitation & $\begin{array}{l}\text { Annual maximum consecutive } \\
\text { 5-day precipitation amount }\end{array}$ & $\mathrm{mm}$ \\
\hline CWD & Consecutive wet days & $\begin{array}{l}\text { Maximum number of consecutive } \\
\text { days when precipitation } \geq 1 \mathrm{~mm}\end{array}$ & days \\
\hline CDD & Consecutive dry days & $\begin{array}{l}\text { Maximum number of consecutive } \\
\text { days when precipitation }<1 \mathrm{~mm}\end{array}$ & days \\
\hline
\end{tabular}

\subsection{Statistical methods}

\subsubsection{Statistical significance testing}

We perform a modified $t$ test, as described in Zwiers and von Storch (1995), to indicate which biases between the model run and observations are statistically significant for $T_{\mathrm{MAX}}$, $T_{\text {MIN }}$ and total precipitation $\left(P_{\text {TOT }}\right)$. This modified $t$ test accounts for autocorrelation within the time series. Total precipitation, $T_{\mathrm{MAX}}$ and $T_{\mathrm{MIN}}$ are robust observations for long time series and are the underlying data of the extreme indices.

\subsubsection{Probability density functions and skill score}

We calculate probability density functions (PDFs) for $T_{\mathrm{MIN}}$ and $T_{\text {MAX }}$ from the model and observations to investigate which part of the distributions are most important for the biases. The PDFs are based on $T_{\mathrm{MAX}}$ (time, lat, lon), $T_{\mathrm{MIN}}$ (time, lat, lon) containing monthly means for the 1951-2011 time period for the corresponding season and region. We use R's kernel density function, using the default Gaussian smoothing kernel and a bandwidth estimated via normal reference distribution to plot the lines.

We use a skill score defined in Perkins et al. (2007) which measures the overlap between two PDFs by summing up the cumulative minimum probability at each bin. A perfect skill equals one, whereas values close to zero indicate a poor agreement. We use a bin width of $0.5^{\circ} \mathrm{C}$ for the calculation of the histograms as in Perkins et al. (2007).

\section{Results}

First we present the seasonal averages of $T_{\text {MAX }}, T_{\text {MIN }}$ and $P_{\text {TOT }}$. Daily $T_{\text {MAX }}, T_{\text {MIN }}$ and total precipitation data form the basis for the calculation of the ETCCDI indices. The seasonal averages are calculated over December-January-February (DJF), March-April-May (MAM), June-July-August (JJA) and September-October-November (SON). Then we present biases in several (annual) ETCCDI indices before investigating the causes of the differences between model and observations.

\subsection{Minimum and maximum temperature and total precipitation}

We calculate seasonal averages from daily $T_{\mathrm{MIN}}$ and $T_{\mathrm{MAX}}$ for the 1951-2011 period from ACCESS1.3b (Figs. 1a and $2 \mathrm{a}$ ) and compare them to gridded observations from HadGHCND (Figs. 1b and 2b). The overall seasonal patterns are reproduced reasonably well by ACCESS. $T_{\text {MAX }}$ shows a negative bias in most regions except North America and parts of southeastern Europe and Africa in JJA (Fig. 1c), whereas $T_{\text {MIN }}$ shows a positive bias almost globally (Fig. 2 c), except for the Arctic and Himalayas. Since HadGHCND does not have a complete coverage in all grid boxes over the whole time period we analysed, regional biases can be influenced by temperature trends, e.g. in East Africa where there is only data between $\sim 1960$ and 1990 (Caesar et al., 2006). The opposing $T_{\mathrm{MAX}}$ and $T_{\mathrm{MIN}}$ biases commonly lead to a good simulation of the mean temperature (Kowalczyk et al., 2013, Fig. 10). Only North America and southeastern Europe 
a) $\quad$ ACCESS $\mathrm{T}_{\operatorname{MAX}}\left[{ }^{\circ} \mathrm{C}\right]$

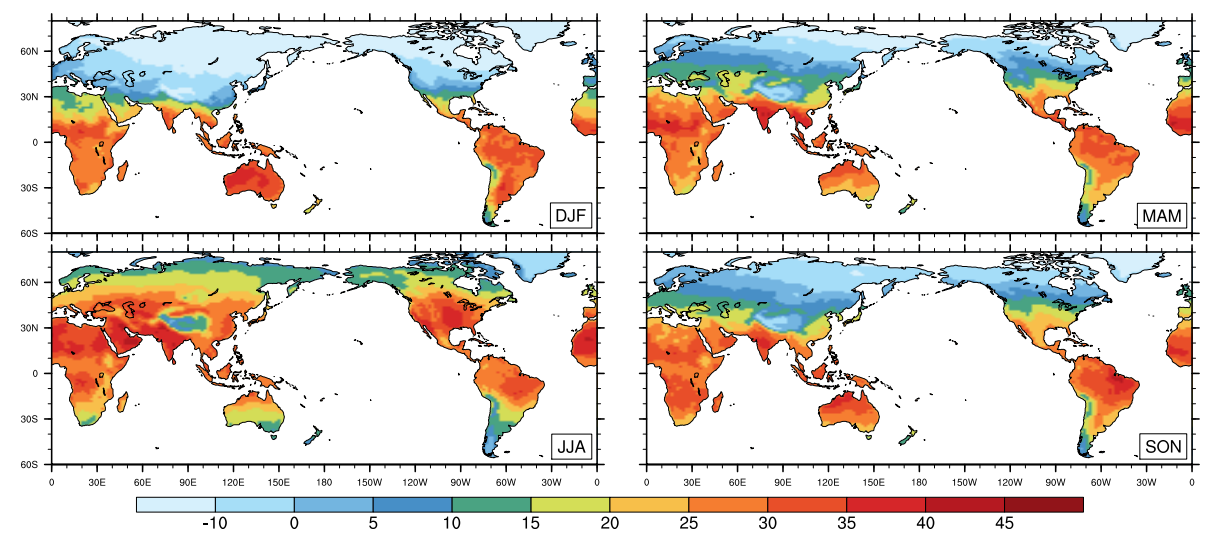

b) $\quad$ HadGHCND T $T_{\text {MAX }}\left[{ }^{\circ} \mathrm{C}\right]$

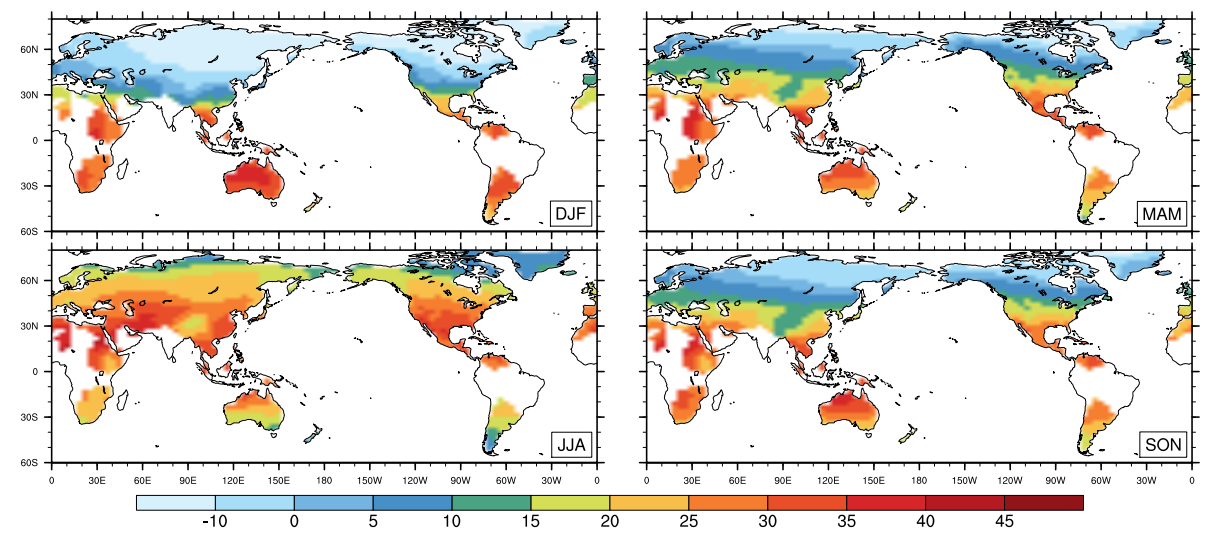

c) $\quad \mathrm{T}_{\text {MAX }}$ bias ACCESS-HadGHCND $\left[{ }^{\circ} \mathrm{C}\right]$

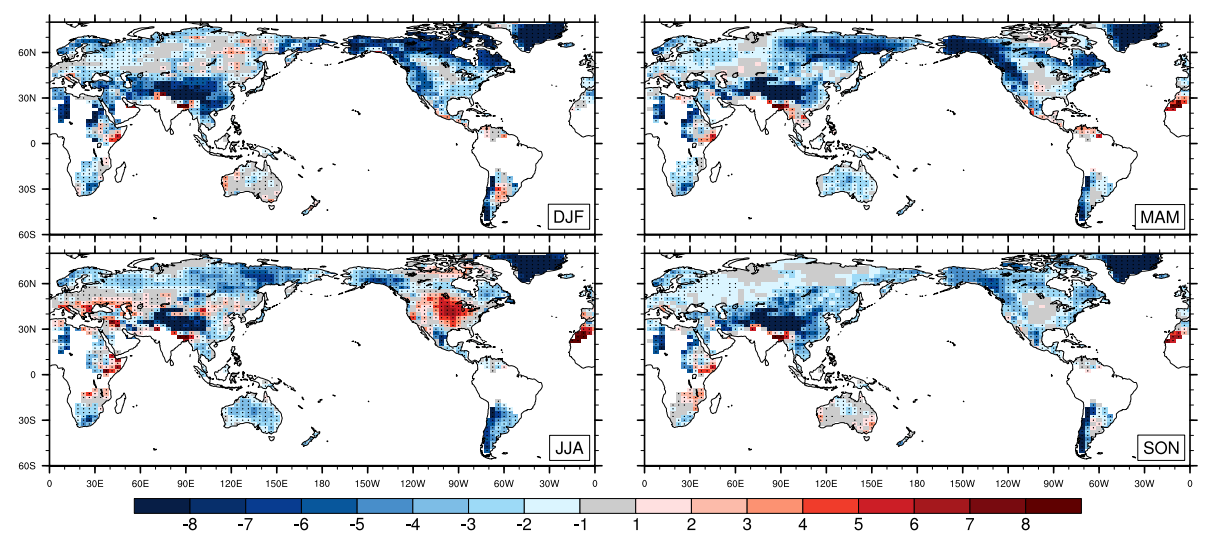

Fig. 1. Daily $T_{\text {MAX }}$ for ACCESS1.3b (a), HadGHCND (b) and bias (c). Unshaded areas in (b) and (c) reflect missing observation data. The considered time period is the overlapping time period between model run and observations, 1951-2011. Stippling in (c) indicates areas where bias is statistically significant based on the modified $t$ test.

show a positive bias in boreal summer (JJA) in $T_{\mathrm{MAX}}$ as well as $T_{\mathrm{MIN}}$, which results in a pronounced positive bias in JJA mean temperature especially in North America (not shown). Positive temperature biases in central Eurasia and North America were also found by Kowalczyk et al. (2013), who linked them to underestimation of precipitation. The North
American bias in JJA was previously associated with an underestimation of clouds in the area of up to $30 \%$ (Franklin et al., 2013a). Overall, however, Fig. 1 suggests a cold bias in $T_{\mathrm{MAX}}$ in most regions and in most seasons, commonly reaching $4{ }^{\circ} \mathrm{C}$ and regionally exceeding $7{ }^{\circ} \mathrm{C}$. The key exception to this is in JJA where there is a warm bias in the Northern 
a) $\quad$ ACCESS $\mathrm{T}_{\text {MIN }}\left[{ }^{\circ} \mathrm{C}\right]$

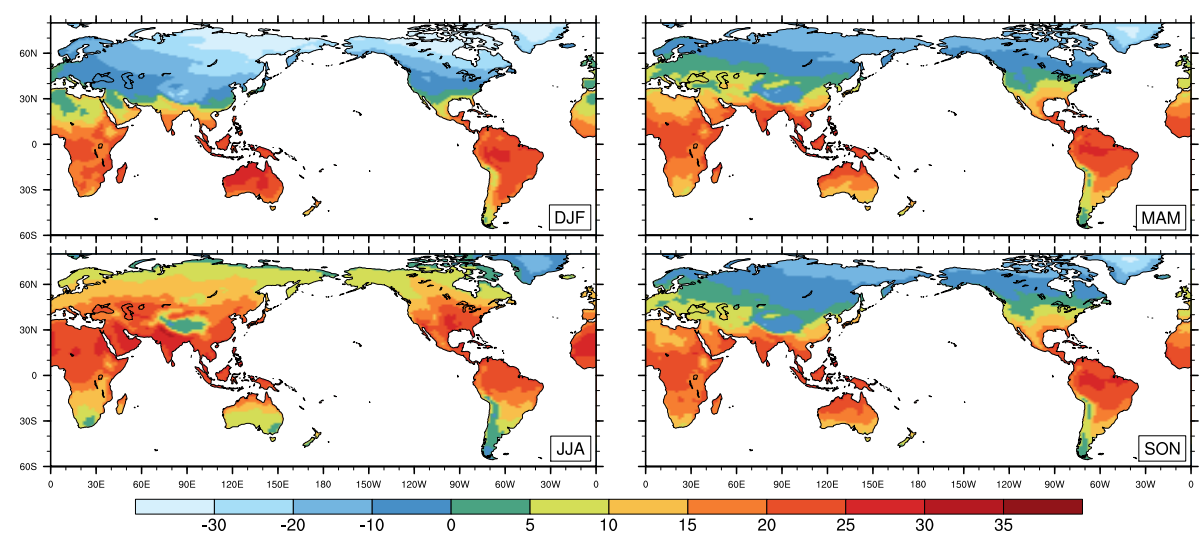

b)

HadGHCND $\mathrm{T}_{\mathrm{MN}}\left[{ }^{\circ} \mathrm{C}\right]$

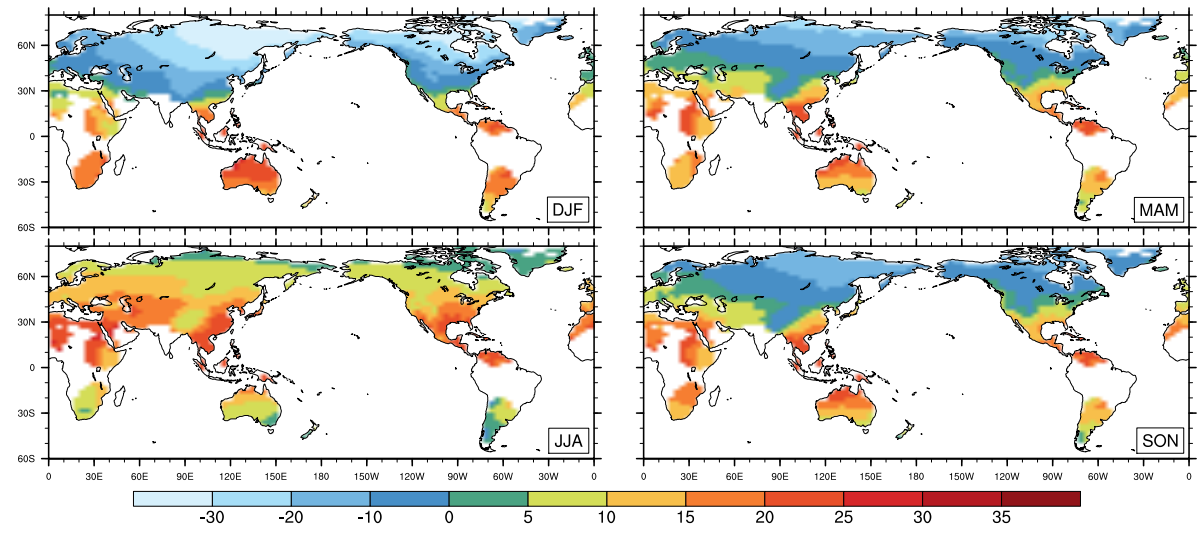

c) $\quad \mathrm{T}_{\text {MIN }}$ bias ACCESS-HadGHCND [ $\left.{ }^{\circ} \mathrm{C}\right]$

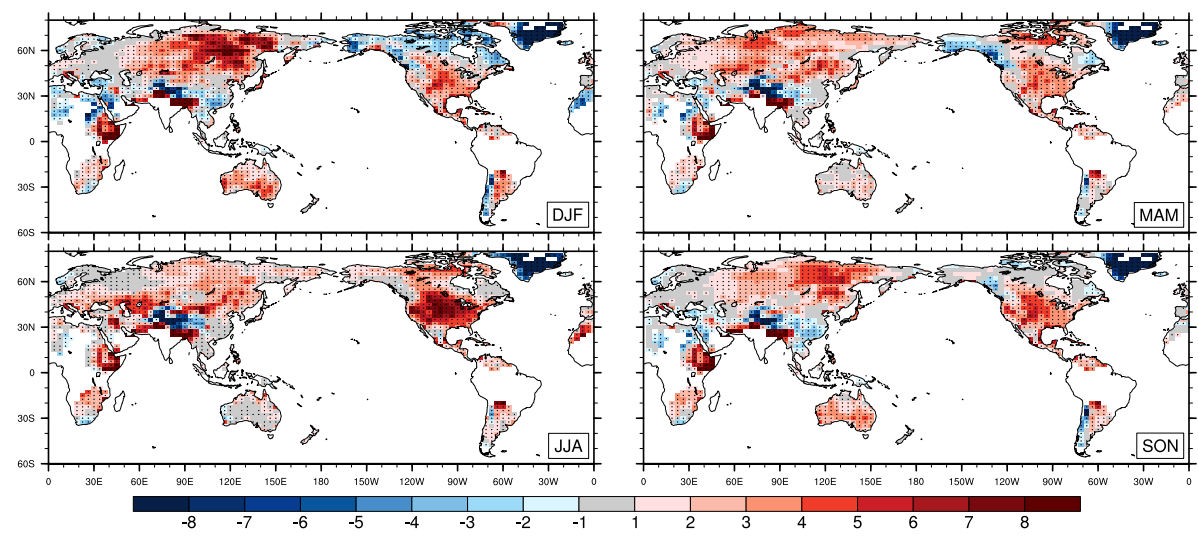

Fig. 2. Daily $T_{\mathrm{MIN}}$ for ACCESS1.3b (top row), HadGHCND (middle row) and bias (bottom row). Unshaded areas in (b) and (c) reflect missing observation data. The considered time period is the overlapping time period between model run and observations, 1951-2011. Stippling in (c) indicates areas where bias is statistically significant based on the modified $t$ test.

Hemisphere mid-latitudes of $\sim 2{ }^{\circ} \mathrm{C}$, exceeding $5^{\circ} \mathrm{C}$ over North America. Figure 2, in contrast, suggests a warm bias of $\sim 2{ }^{\circ} \mathrm{C}$ in $T_{\mathrm{MIN}}$ almost everywhere, exceeding $5^{\circ} \mathrm{C}$ over North Asia in DJF, and North America in JJA. Global patterns of $P_{\text {TOT }}$ are well represented in ACCESS1.3b compared to GPCP during the 1980-2012 time period (Fig. 3a and 3b).
ACCESS1.3b tends to overestimate total seasonal precipitation (Fig. 3c) in most regions, although there is a small underestimate over Europe in most seasons. The wet precipitation bias is largest in the tropics (exceeding $5 \mathrm{mmd}^{-1}$ ), but elsewhere it is generally small $\left(<1 \mathrm{mmd}^{-1}\right)$. A large negative precipitation bias exists in India in JJA and SON where the 


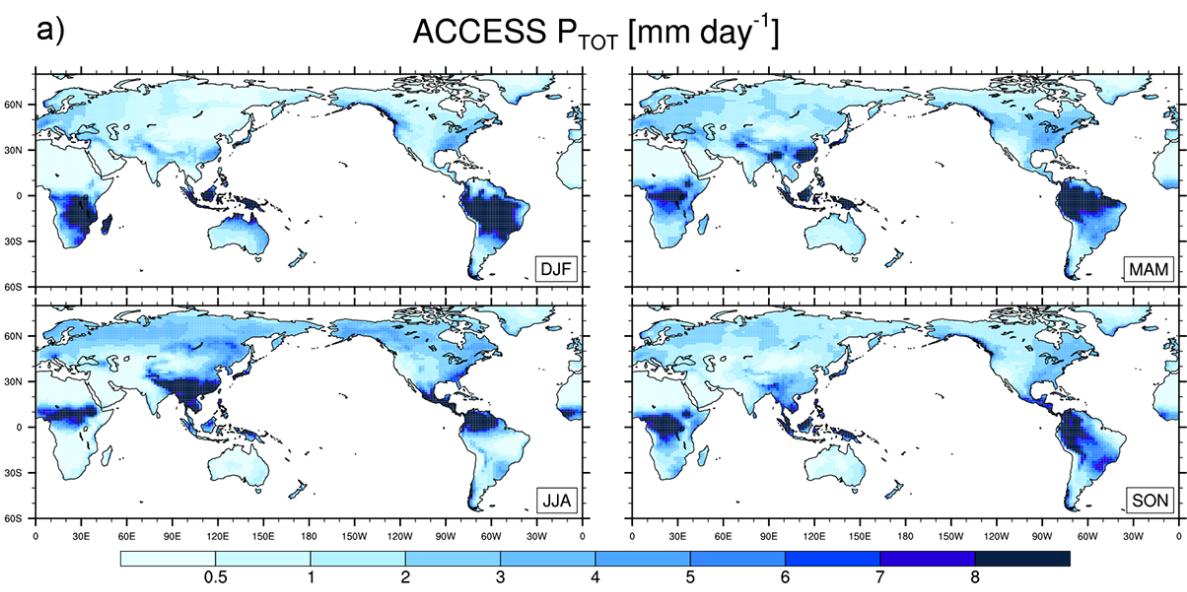

b)

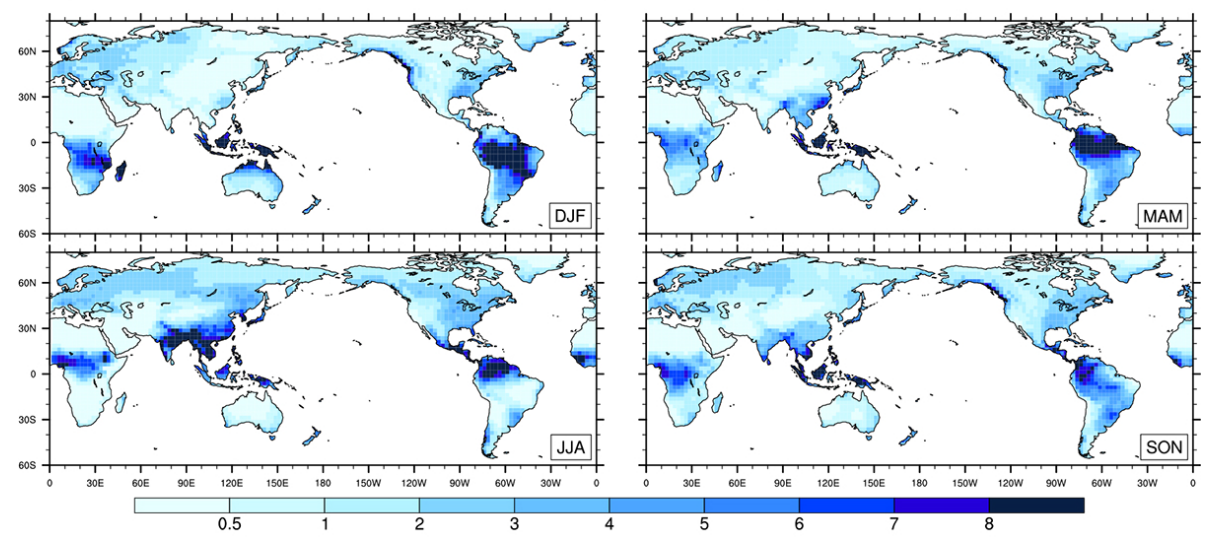

c) $\quad \mathrm{P}_{\text {TOT }}$ bias ACCESS-GPCP $\left[\mathrm{mm} \mathrm{day}^{-1}\right]$

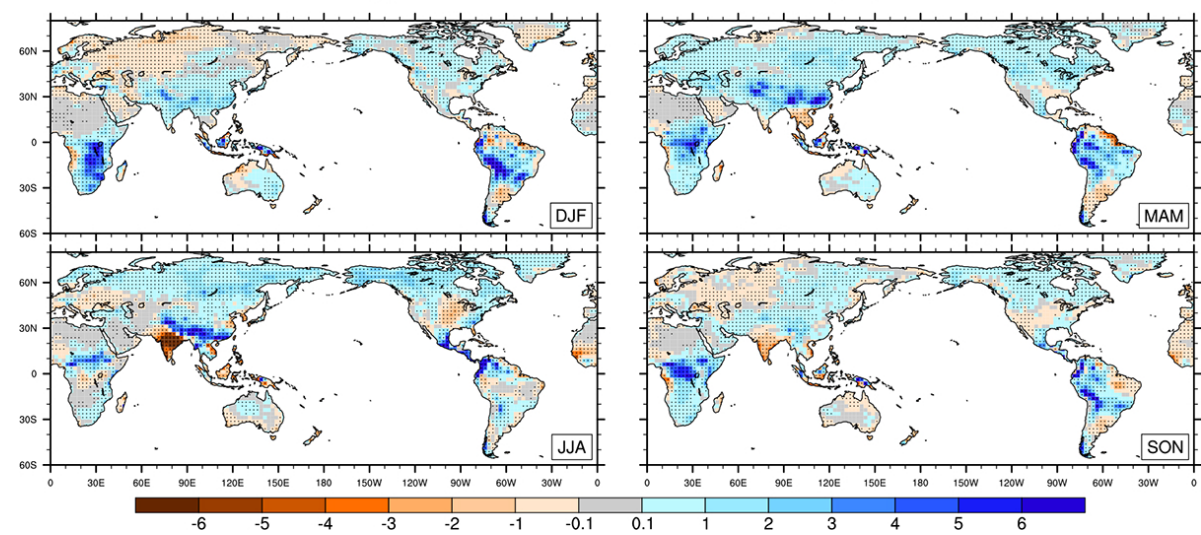

Fig. 3. Total precipitation for ACCESS1.3b (a), GPCP (b) and bias (c). The considered time period is the overlapping time period between model run and observations, 1980-2012. Stippling in (c) indicates areas where bias is statistically significant based on the modified $t$ test.

monsoon is displaced. This bias has previously been reported by Kowalczyk et al. (2013) and Bi et al. (2013). These biases are statistically significant, indicated by stippling, in most regions.

\subsection{ETCCDI indices}

Results for ETCCDI indices in ACCESS1.3b are compared to the HadEX2 data set. Since the indices are calculated for station data in HadEX2 and then gridded, one would expect that model output might appear smoother with less extremes than the observational data set (Donat et al., 2013b). 
a)

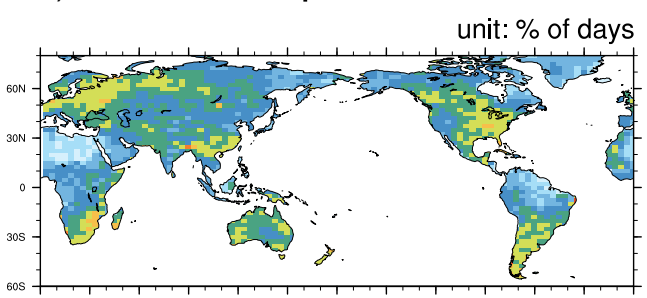

c)

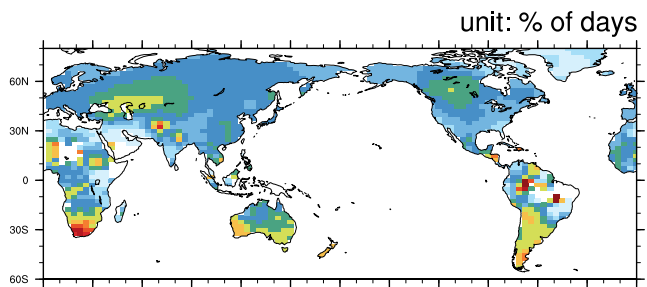

e) TN10p: ACCESS-HADEX2

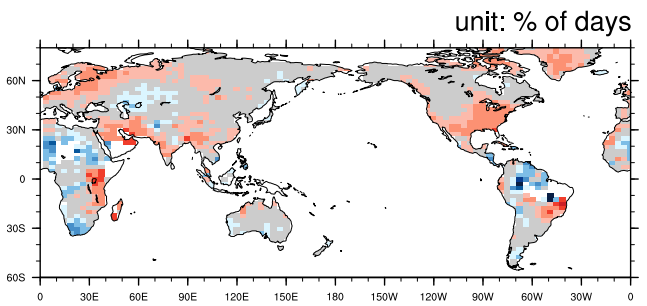

g) area-weighted global average

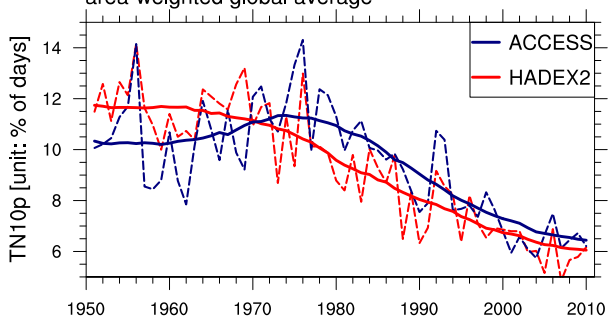

b)

TX10p ACCESS

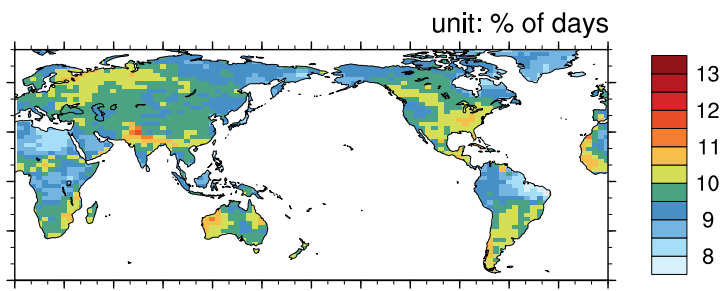

d)

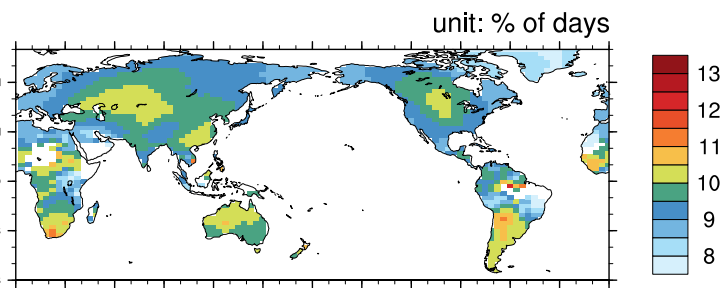

f) TX10p: ACCESS-HADEX2

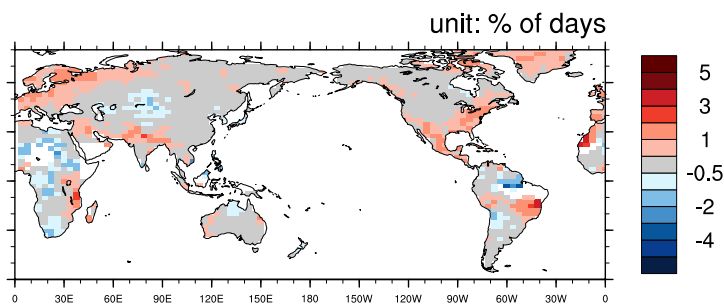

h)

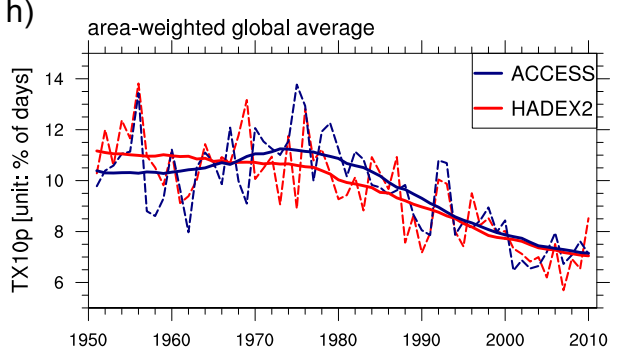

Fig. 4. Annual cool nights (TN10p, left column) and cool days (TX10p, right column) for ACCESS1.3b (a, b), HadEX2 (c, d), bias (e, f) and the global average time series showing trends $(\mathbf{g}, \mathbf{h})$. Unshaded areas reflect missing observation data. ACCESS data were masked depending on the availability of HadEX2 before calculating the global average. We applied a static masked only including grid points where more than 50 years of data (out of 60) were available to calculate the global average. The solid lines in (g) and (h) show the time series smoothed by a 21-year Gaussian filer, while the dashed lines show the yearly values.

In particular, one would expect precipitation-based extremes estimates calculated from station-based observations to be more intense. However, we did not find a general underestimation of the variability in the extreme indices in the model.

The percentile-based indices are expected not to differ much from HadEX2, since the percentiles are calculated from the model data and are $10 \%$ on average during the base period (1961-1990) per definition. Hence, differences between ACCESS and HadEX2 are mainly driven by different trends and do not depend on biases in absolute values of $T_{\mathrm{MAX}}$ and $T_{\mathrm{MIN}}$. The two indices that examine cold extremes, cool nights (TN10p) and cool days (TX10p) are shown in Fig. 4. The ACCESS1.3b model represents the global patterns of both TN10p (Fig. 4e) and TX10p (Fig. 4f) reasonably well. ACCESS1.3b also captures the decreasing trends in TN10p (Fig. 4g) and TX10p (Fig. 4h) over the period 1951 to 2010. ACCESS underestimates the total trend in TN10p because values are underestimated by $\sim 2 \%$ at the beginning of the simulation and the model data show an increasing trend until the 1980s. After $\sim 1980$, the trends are captured well such that the model simulates a close value to the observations of $\sim 6 \%$ of days by 2010 . The trend in TX10p is similar to TN10p, but differences are smaller between ACCESS and HadEX2. Both show a decrease from $\sim 11 \%$ to $7 \%$ of days. The global patterns in the two indices representing hot extremes (warm nights, 
a)

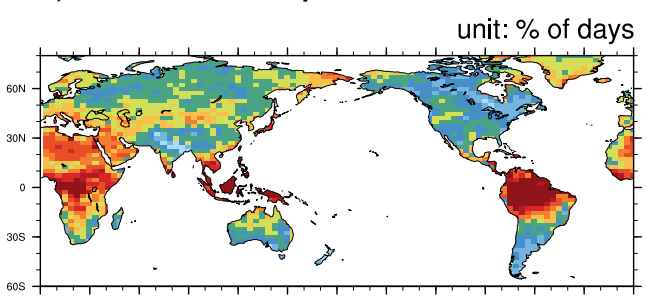

c)

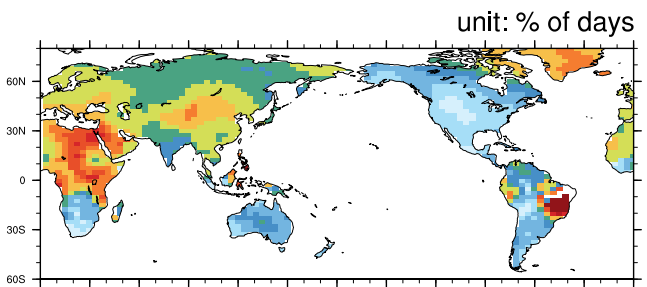

e) TN90p: ACCESS-HADEX2

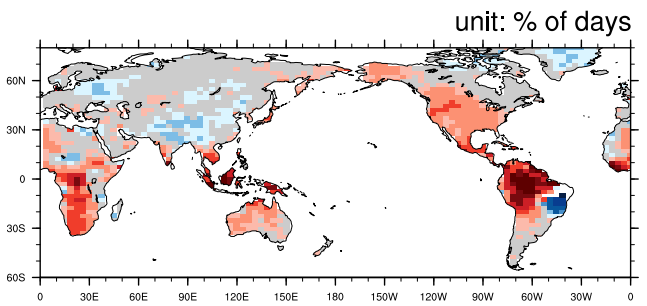

g) area-weighted global average

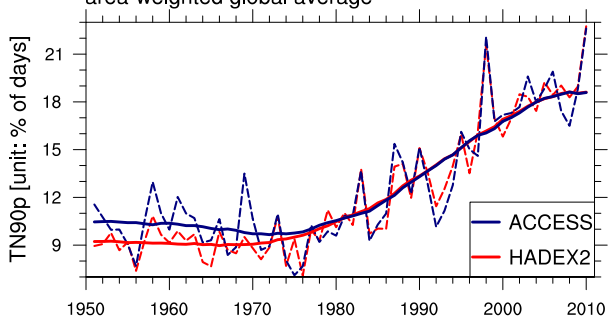

b)

TX90p ACCESS

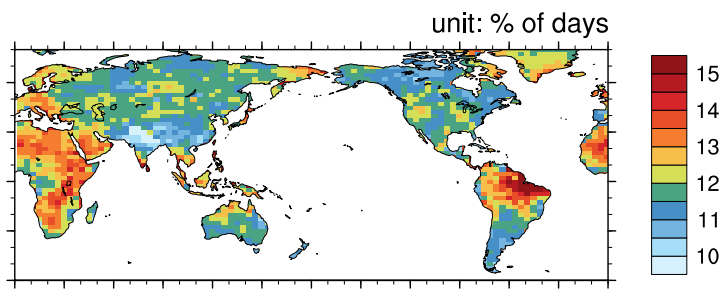

d)

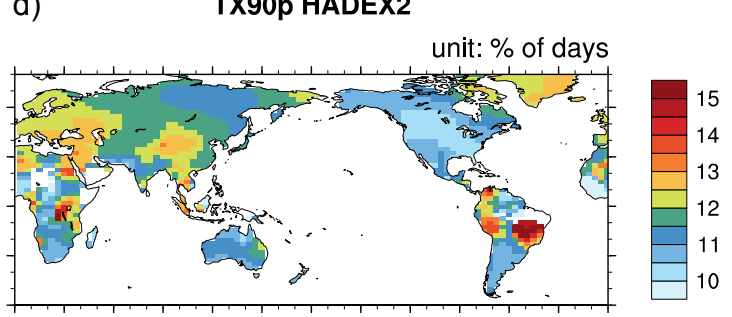

f) TX90p: ACCESS-HADEX2

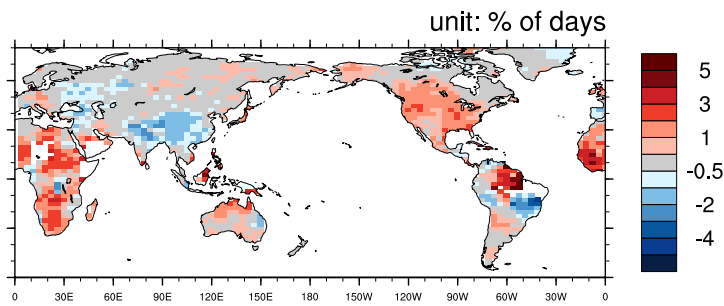

h)

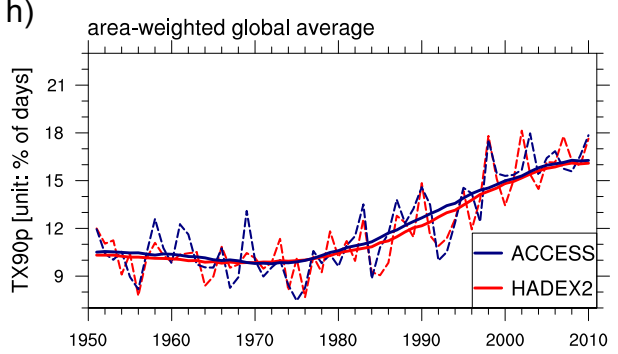

Fig. 5. Annual warm nights (TN90p, left column) and warm days (TX90p, right column) for ACCESS1.3b (a, b), HadEX2 (c, d), bias (e, f) and the global average time series showing trends $(\mathbf{g}, \mathbf{h})$. Unshaded areas reflect missing observation data. We applied a static masked only including grid points where more than 50 years of data (out of 60) were available to calculate the global average. The solid lines in (g) and (h) show the time series smoothed by a 21-year Gaussian filer, while the dashed lines show the yearly values.

TN90p and warm days, TX90p) are also captured well by ACCESS1.3b (Fig. 5). The regional differences for hot extremes are larger than for cold extremes. There is a large overestimate in the occurrence of TN90p in the Southern Hemisphere, particularly over South America, but this difference also affects North America, Australia and southern Africa (Fig. 5e). Similar regions are affected by an overestimation of TX90p (Fig. 5f). Despite these regional differences, ACCESS1.3b estimates the global increasing trends in both TN90p (Fig. 5g) and TX90p (Fig. 5h) remarkably well. We note that this might be because data availability in some of the regions with large differences is too low to pass the requirement of 50+ years of data in HadEX2 to be included in the global average. Also note the close agreement in interannual variability between ACCESS and HadEX2, suggesting a strong influence from sea surface temperatures, which are prescribed here, on hot extremes. The final temperature index is the diurnal temperature range (DTR, Fig. 6). This is simulated poorly by ACCESS $1.3 \mathrm{~b}$ and is globally underestimated by up to $4{ }^{\circ} \mathrm{C}$ (Fig. 6c). This result is anticipated given the seasonal overestimation of $T_{\mathrm{MIN}}$ and underestimation of $T_{\text {MAX }}$. The underestimation of DTR is shown clearly in the global time series (Fig. 6d). We put this large underestimation into context with CMIP-5 simulations and reanalysis in the discussion in Sect. 4. There is no clear trend in DTR in the model and the trend in HadEX2 is very hard to see because of the scale of the figure. However, DTR decreases from $11.2^{\circ} \mathrm{C}$ to $11^{\circ} \mathrm{C}$ in $\operatorname{HadEX} 2$ and was shown to 
a)

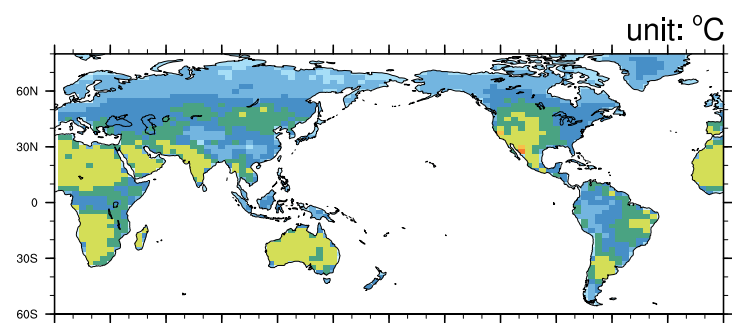

b)

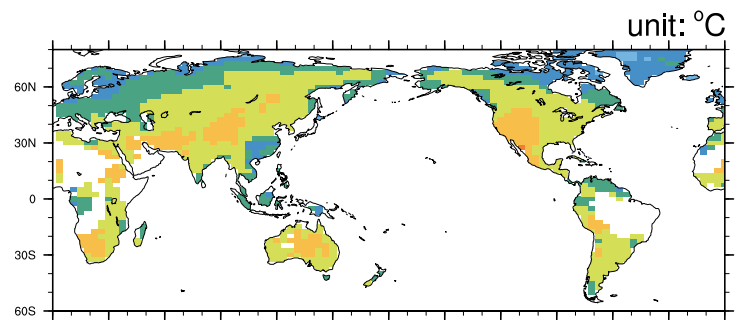

c)

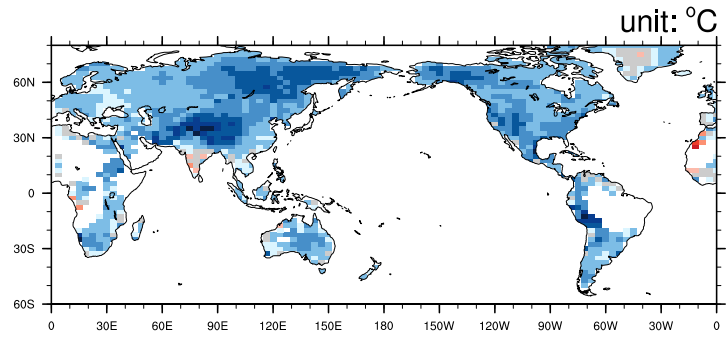

d)

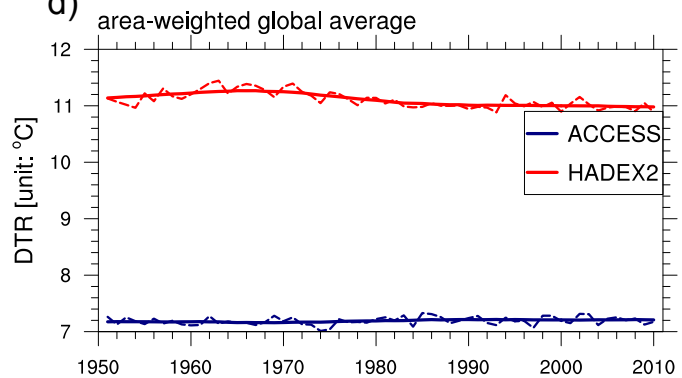

Fig. 6. Annual diurnal temperature range (DTR) for ACCESS1.3b (a), HadEX2 (b), bias (c) and the global average time series showing trends (d). Unshaded areas reflect missing observation data. We applied a static masked only including grid points where more than 50 years of data (out of 60) were available to calculate the global average. The solid lines in (g) show the time series smoothed by a 21-year Gaussian filer, while the dashed lines show the yearly values.

have a significant decreasing trend by Donat et al. (2013b) of $\sim 0.05^{\circ} \mathrm{C}$ per decade.

The annual maximum consecutive 1-day precipitation (Rx1day) shows both, regions of overestimation and underestimation (Fig. 7). The pronounced underestimation over India is clearly related to the missing monsoon (Fig. 7c). The smaller underestimation in North America is related to a)

\section{Rx1day ACCESS}

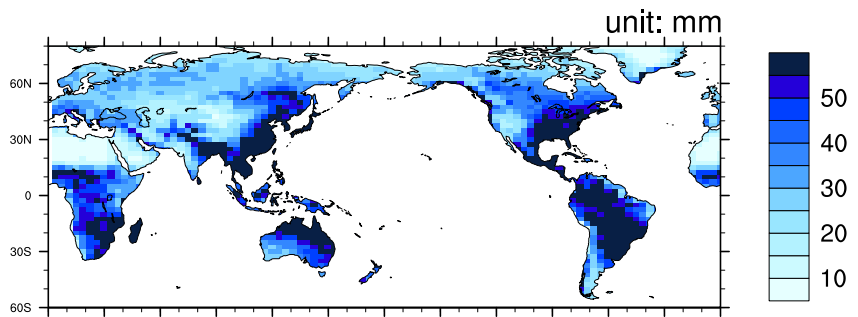

b)

\section{Rx1day HADEX2}

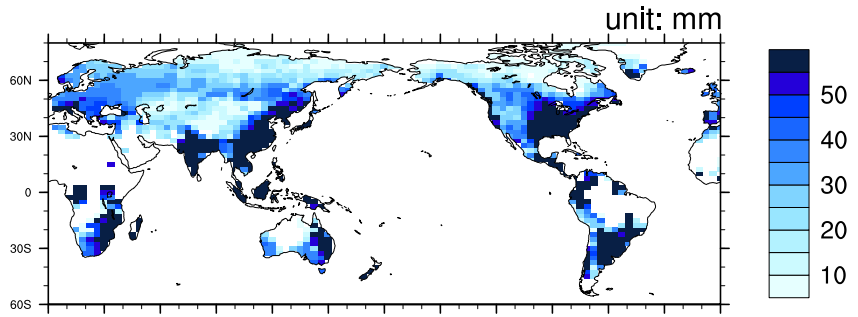

C) Rx1day: ACCESS-HADEX2

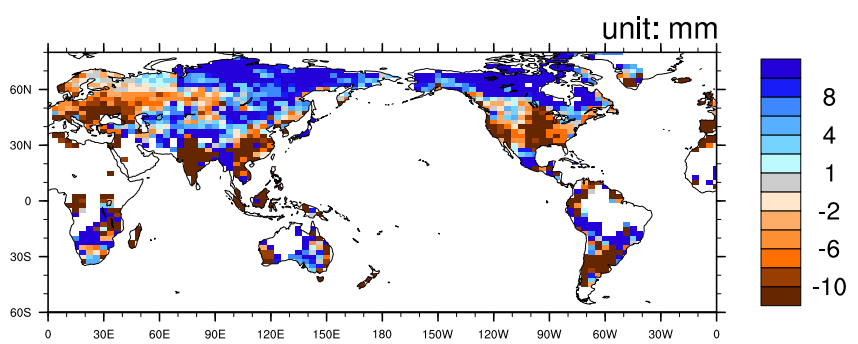

d)

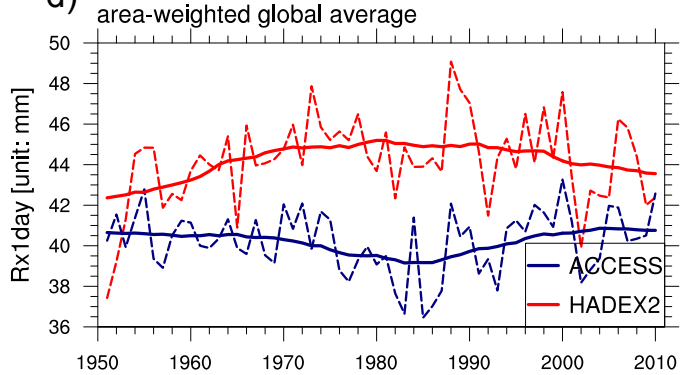

Fig. 7. Annual maximum consecutive 1-day precipitation (Rx1day) for ACCESS1.3b (a), HadEX2 (b), bias (c) and the global average time series showing trends (d). Unshaded areas reflect missing observation data. We applied a static masked only including grid points where more than 50 years of data (out of 60 ) were available to calculate the global average. The solid lines in $(\mathrm{g})$ show the time series smoothed by a 21-year Gaussian filer, while the dashed lines show the yearly values.

the underestimation of summer rainfall. Central Eurasia also shows an underestimation of Rx1day due to the underestimation in total precipitation during summer, autumn and winter. Overall, ACCESS1.3b underestimates Rx1day (Fig. 7d) by $\sim 2-5 \mathrm{~mm}(\sim 5-10 \%)$. However, ACCESS1.3b clearly captures some elements of Rx1day and some of the variability 
a)

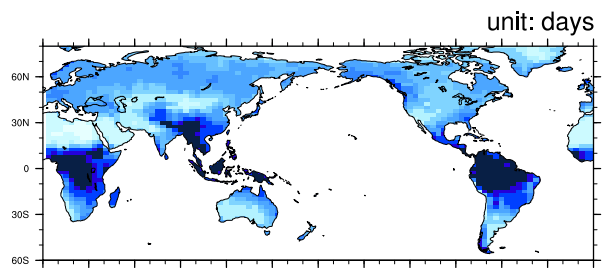

c)

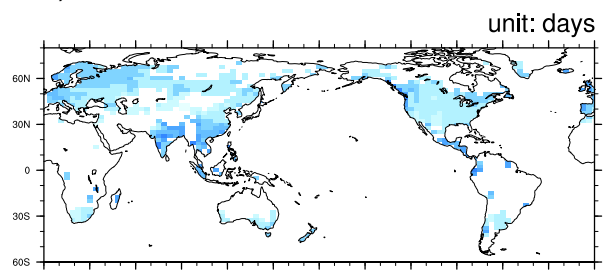

e)
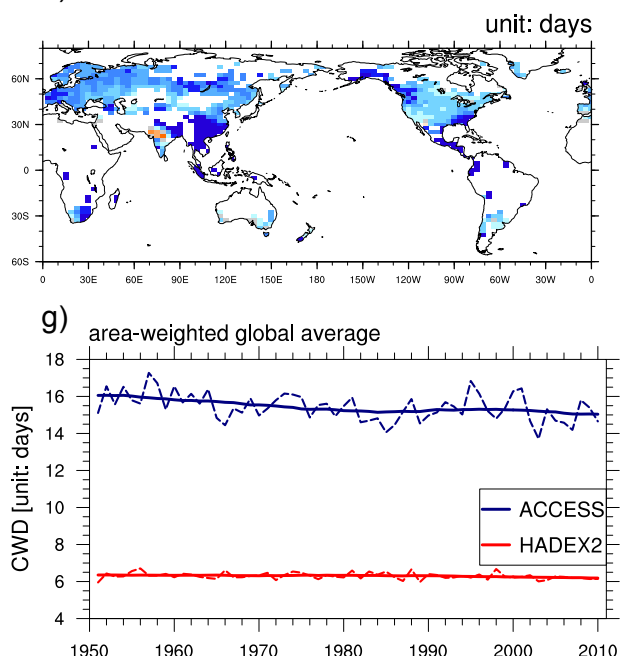

b)

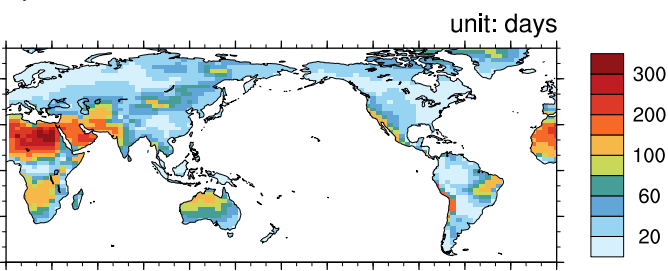

d)

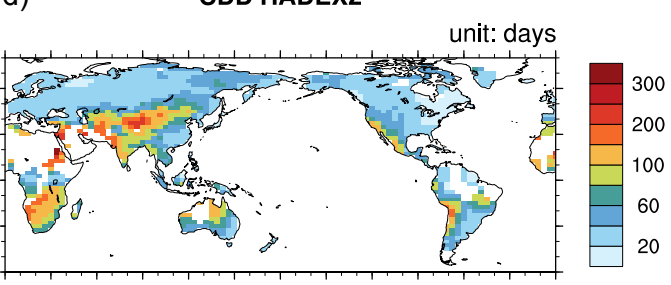

f)

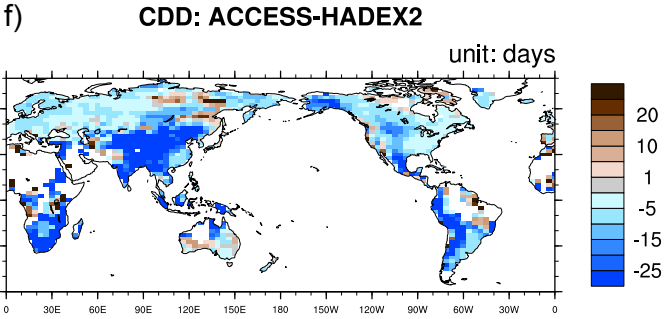

h)

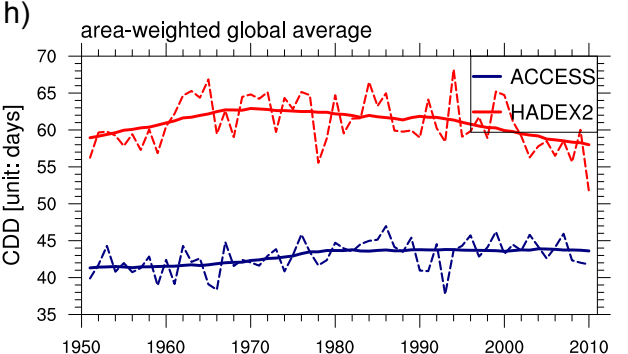

Fig. 8. Annual consecutive wet days (CWD, left column) and consecutive dry days (CDD, right column) for ACCESS1.3b (a, b), HadEX2 (c, d), bias (e, f) and the global average time series showing trends (g, h). Unshaded areas reflect missing observation data. We applied a static masked only including grid points where more than 50 years of data (out of 60) were available to calculate the global average. The solid lines in (g) and (h) show the time series smoothed by a 21-year Gaussian filer, while the dashed lines show the yearly values.

between 1951 and 2010. We also analysed Rx5day (maximum annual consecutive 5-day precipitation) that showed an overestimation from ACCESS on global average (not shown). However, this is an artefact of how we calculate these indices in HadEX2, as maxima out of the monthly maxima, which have a better coverage than the annual maximum (see Sect. 2.3) and the lack of observational data in the tropics. This problem is less pronounced for Rx1day; however, biases around the areas with missing values in HadEX2 have to be taken with care. Consecutive wet days (CWD) are clearly overestimated over the Northern Hemisphere (which is where CWD can be derived due to the low coverage in the Southern Hemisphere), while consecutive dry days (CDD) are underestimated (Fig. 8). There is no clear overall trend in the time series of CWD and CDD (Fig. 8g and h). Overall, there is a clear picture of ACCESS1.3b heavily overestimating consecutive wet days, and underestimating consecutive dry days in those regions where the observations are complete enough to derive these indices.

The biases in extreme precipitation indices are largely influenced by the bias in total precipitation in ACCESS1.3b. This is not a surprise; climate models commonly rain too often, but as low intensity precipitation ("drizzle problem", e.g. Dai, 2006). On a global scale, ACCESS1.3b has too many consecutive wet days, so it rains too often, and underestimates consecutive 1-day precipitation. The biggest bias identified is the underestimation of the diurnal temperature range, due to an overestimation of $T_{\mathrm{MIN}}$ and an underestimation of $T_{\text {MAX }}$. Therefore, the next section focuses on the distributions of $T_{\mathrm{MIN}}$ and $T_{\mathrm{MAX}}$. 
a)

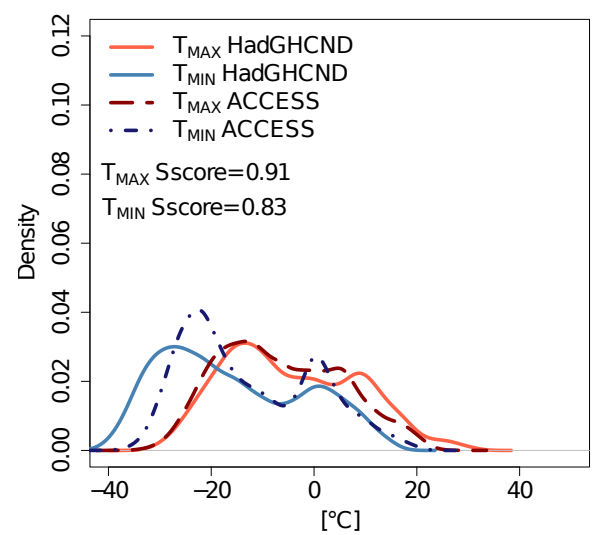

c)

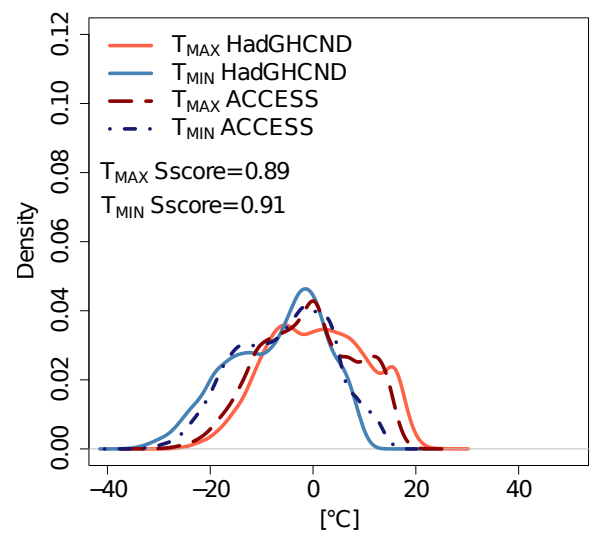

b)

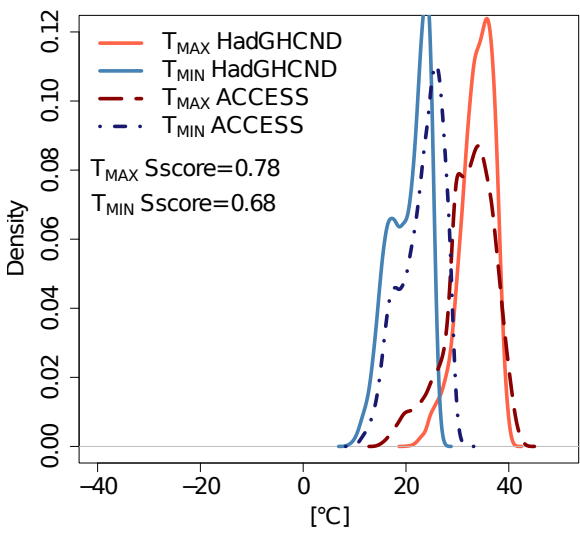

d)

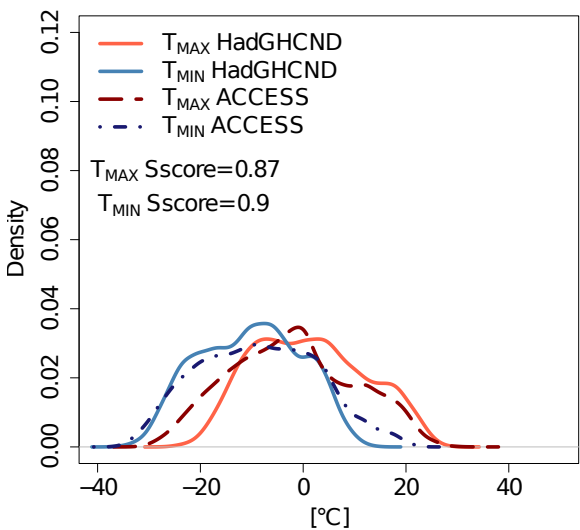

Fig. 9. $T_{\mathrm{MAX}}$ and $T_{\mathrm{MIN}}$ probability density functions for ACCESS1.3b and HadGHCND over Asia, Australia, Europe and North America for DJF (1951-2011) and skill scores for PDFs of $T_{\mathrm{MAX}}$ and $T_{\mathrm{MIN}}$. The skill score is calculated by summing up the lower probability at each bin of two given PDFs, $S_{\text {score }}=\sum_{1}^{n} \operatorname{minimum}\left(Z_{\mathrm{m}}, Z_{\mathrm{o}}\right)$ where $n$ is the number of bins used to calculate the PDFs and $Z_{\mathrm{m}}$ and $Z_{\mathrm{o}}$ correspond to the frequency of values in a bin from the model and the observations, respectively.

\subsection{Probability density functions of $\boldsymbol{T}_{\mathrm{MAX}}$ and $\boldsymbol{T}_{\mathrm{MIN}}$}

The probability density functions (PDFs) of $T_{\mathrm{MAX}}$ and $T_{\mathrm{MIN}}$ for ACCESS1.3b and the HadGHCND data set are shown in Fig. 9 (DJF) and Fig. 10 (JJA). We restrict our analysis of the PDFs to four regions with good data coverage in HadGHCND. These regions are defined in Table 3 and correspond to Asia, Australia, Europe and North America. The results from the PDFs are summarised in each panel using the skill score defined by Perkins et al. (2007) which measures the overlap of the PDFs (perfect agreement is a skill score of 1.0).

For DJF, the three northern hemispheric regions (Asia, Europe, and North America) reproduce the PDFs of the observational data set well. In Asia (Fig. 9a), the lower tail of the $T_{\text {MAX distribution is almost perfectly captured. The upper }}$ tail is also captured well, although there is a small deviation between 10 and $20^{\circ} \mathrm{C}$. In $T_{\mathrm{MIN}}$ the upper tail is well reproduced by ACCESS1.3b, but the lower tail shows a bias of $\sim 5^{\circ} \mathrm{C}$ with too frequent $T_{\mathrm{MIN}}$ simulated around $-20^{\circ} \mathrm{C}$. In North America (Figure 9d), the biases are the opposite; the upper tail of $T_{\mathrm{MAX}}$ is better captured than the lower tail, while the lower tail of the $T_{\mathrm{MIN}}$ distribution is reproduced well. For Europe (Fig. 9c), both $T_{\mathrm{MAX}}$ and $T_{\mathrm{MIN}}$ distributions only show small deviations from the observations. For Australia (Fig. 9b), the upper tail of $T_{\mathrm{MAX}}$ is reasonably captured, but the mean of $T_{\mathrm{MAX}}$ is underestimated and the lower tail shows a bias of $\sim 5^{\circ} \mathrm{C}$. The lower tail of $T_{\mathrm{MIN}}$ in Australia is better captured than the upper tail, but the whole PDF of $T_{\mathrm{MIN}}$ is shifted to the right in the model. Overall the PDF for both $T_{\mathrm{MAX}}$ and $T_{\mathrm{MIN}}$ are simulated with a skill score exceeding 0.8 for all regions except Australia in DJF. There is a clear problem with the PDF for $T_{\mathrm{MAX}}$ in Australia in DJF linked to a large bias associated with the lower tail of the distribution.

In JJA (Fig. 10), Australia (Fig. 10b) reproduces the distributions of $T_{\mathrm{MIN}}$ and $T_{\mathrm{MAX}}$ better than the northern hemispheric regions Asia and North America. The lower tail of 
a)

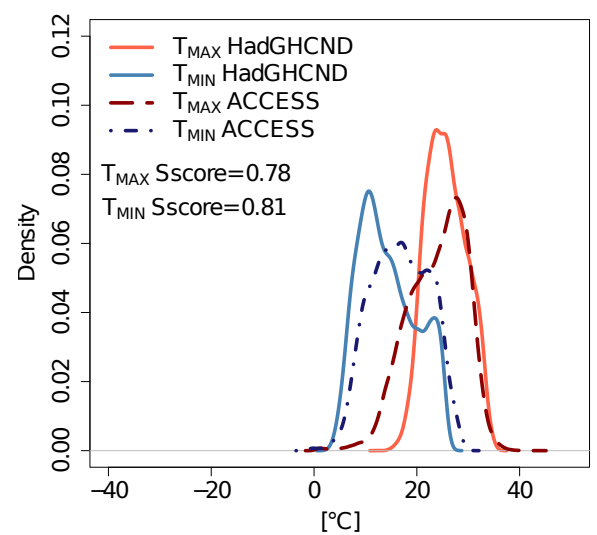

c)

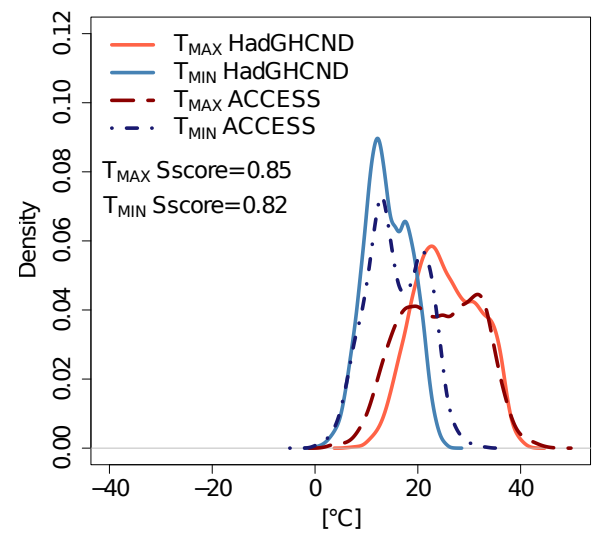

b)

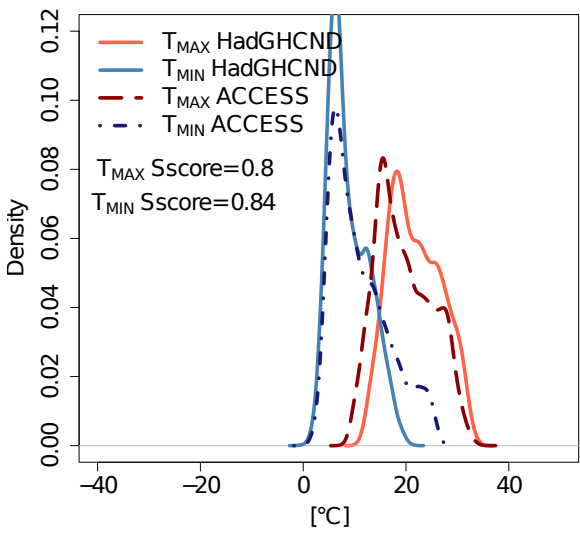

d)

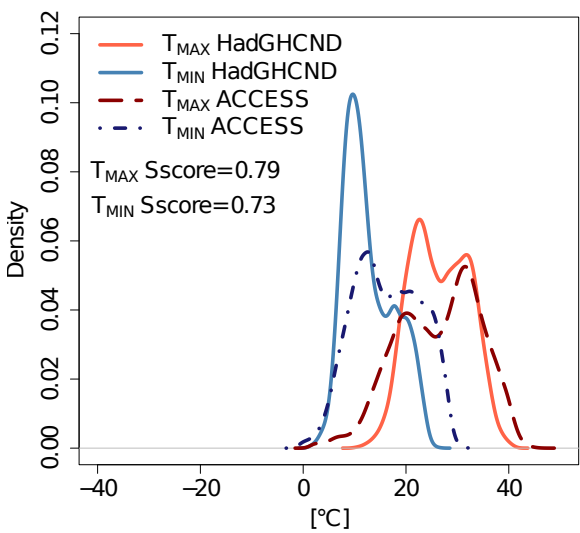

Fig. 10. $T_{\text {MAX }}$ and $T_{\text {MIN }}$ probability density functions for ACCESS1.3b and HadGHCND over Asia, Australia, Europe and North America for JJA (1951-2011) and skill scores for PDFs of $T_{\text {MAX }}$ and $T_{\text {MIN (as in Fig. 9). }}$

Table 2. Data sets used for evaluation.

\begin{tabular}{|c|c|c|c|c|}
\hline Abbreviation & Description/Name & Time & Resolution & Reference \\
\hline HadEX2 & $\begin{array}{l}\text { Data set containing } \\
\text { ETCCDI indices }\end{array}$ & $1901-2010$ & $2.5^{\circ} \times 3.75^{\circ}$ & Donat et al. (2013b) \\
\hline HadGHCND & $\begin{array}{l}\text { Gridded daily temperature } \\
\text { data set }\end{array}$ & 1951-now & $2.5^{\circ} \times 3.75^{\circ}$ & Caesar et al. (2006) \\
\hline GPCP & $\begin{array}{l}\text { Global Precipitation Clima- } \\
\text { tology Project Version-2 }\end{array}$ & 1979-now & $2.5^{\circ} \times 2.5^{\circ}$ & Adler et al. (2003) \\
\hline CERES & $\begin{array}{l}\text { Clouds and the Earth's } \\
\text { Radiant Energy System }\end{array}$ & 2001-2009 & $1^{\circ} \times 1^{\circ}$ & Kato et al. (2013) \\
\hline GLEAM & $\begin{array}{l}\text { Global Land-surface Evaporation: } \\
\text { the Amsterdam Methodology }\end{array}$ & 1984-2007 & $0.25^{\circ} \times 0.25^{\circ}$ & Miralles et al. (2011) \\
\hline $\begin{array}{l}\text { LandFlux- } \\
\text { EVAL }\end{array}$ & $\begin{array}{l}\text { Land evapotranspiration } \\
\text { multi-data synthesis }\end{array}$ & 1985-2005 & $1^{\circ} \times 1^{\circ}$ & Mueller et al. (2013) \\
\hline
\end{tabular}

$T_{\text {MIN }}$ is almost perfect but the upper tail has a bias of $\sim 5^{\circ} \mathrm{C}$. For $T_{\mathrm{MAX}}$ the upper tail is reproduced well, but the lower tail is shifted to the left in the model by about $3^{\circ} \mathrm{C}$. Overall, however, ACCESS1.3b captures the $T_{\mathrm{MIN}}$ and $T_{\mathrm{MAX}}$ for Australia in JJA with a skill score exceeding 0.8. The PDFs for the Northern Hemisphere region are less well captured than in DJF (Fig. 10a, c and d), with half the skill scores below 0.8 for these regions. Europe (Fig. 10c) captures the lower tail for $T_{\mathrm{MIN}}$ well, but the upper tail is slightly overestimated. For $T_{\text {MAX }}$, the PDF is shifted to the left in the model 
Table 3. Subregions used for probability density functions

\begin{tabular}{ll}
\hline Name & Definition (latitude $\left[^{\circ}\right]$, longitude $\left[^{\circ}\right]$ of region corners) \\
\hline Asia & $\left(20^{\circ} \mathrm{N}, 145^{\circ} \mathrm{E}\right)\left(20^{\circ} \mathrm{N}, 100^{\circ} \mathrm{E}\right)\left(60^{\circ} \mathrm{N}, 100^{\circ} \mathrm{E}\right)\left(60^{\circ} \mathrm{N}, 145^{\circ} \mathrm{E}\right)$ \\
Australia & $\left(50^{\circ} \mathrm{S}, 155^{\circ} \mathrm{E}\right)\left(50^{\circ} \mathrm{S}, 110^{\circ} \mathrm{E}\right)\left(10^{\circ} \mathrm{S}, 110^{\circ} \mathrm{E}\right)\left(10^{\circ} \mathrm{S}, 155^{\circ} \mathrm{E}\right)$ \\
Europe & $\left(30^{\circ} \mathrm{N}, 75^{\circ} \mathrm{E}\right)\left(30^{\circ} \mathrm{N}, 10^{\circ} \mathrm{W}\right)\left(70^{\circ} \mathrm{N}, 10^{\circ} \mathrm{W}\right)\left(70^{\circ} \mathrm{N}, 75^{\circ} \mathrm{E}\right)$ \\
North America & $\left(25^{\circ} \mathrm{N}, 60^{\circ} \mathrm{W}\right)\left(25^{\circ} \mathrm{N}, 130^{\circ} \mathrm{W}\right)\left(60^{\circ} \mathrm{N}, 130^{\circ} \mathrm{W}\right)\left(60^{\circ} \mathrm{N}, 60^{\circ} \mathrm{W}\right)$ \\
\hline
\end{tabular}

a)

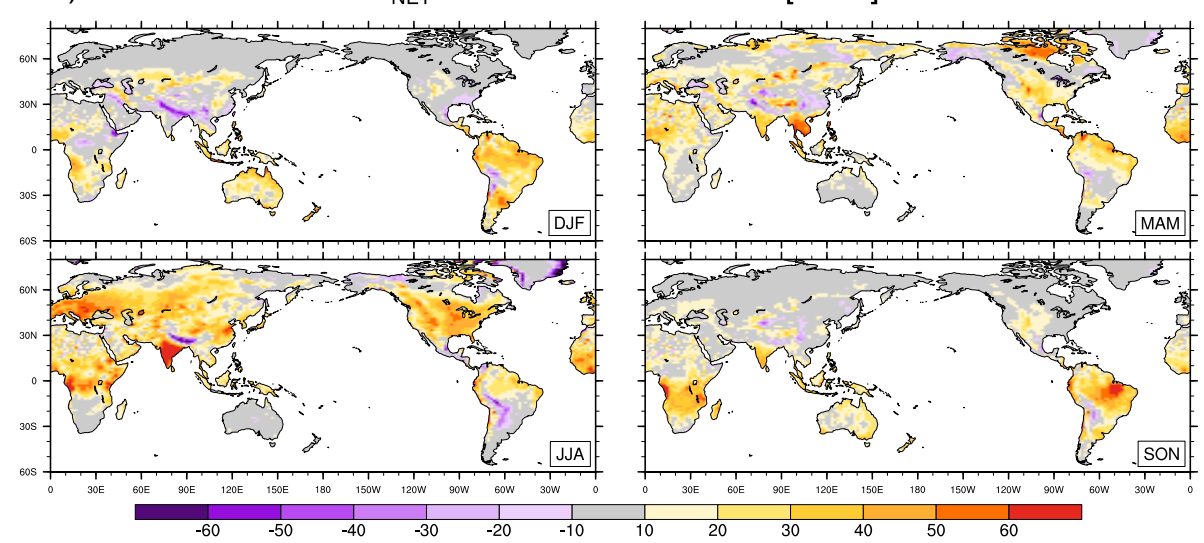

b)

LW $_{\mathrm{NET}}$ bias: ACCESS-CERES [ $\mathrm{Wm}^{-2}$ ]

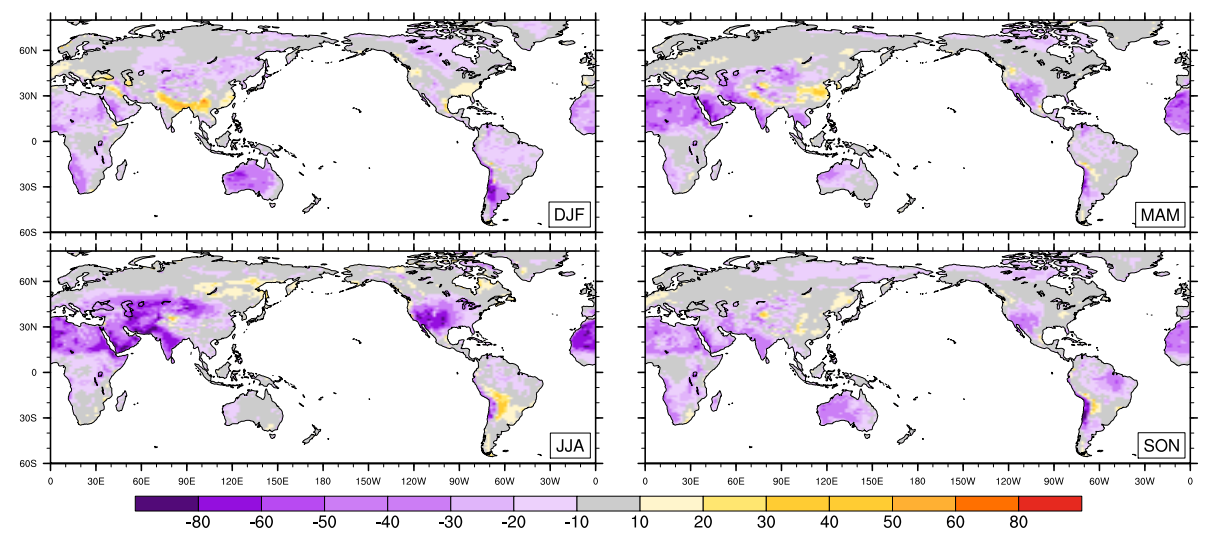

Fig. 11. Biases between ACCESS1.3b and CERES in net shortwave radiation (a) and net longwave radiation (b). The considered time period is the overlapping time period between model run and observations, 2001-2009.

by $\sim 3{ }^{\circ} \mathrm{C}$ and the mean of the distribution is underestimated. However, for Europe the skill scores in JJA are still larger than 0.8. $T_{\text {MAX }}$ in Asia (Fig. 10a) shows a similar picture, although the biases are larger than in Europe. $T_{\mathrm{MIN}}$ is shifted to the right, especially the main peak that is also underestimated leading to a low overall skill score. In North America (Fig. 10d), only the lower tail of $T_{\mathrm{MIN}}$ is reasonably reproduced by the model, the main peak is underestimated and the upper tail shifted to the right by $\sim 5^{\circ} \mathrm{C}$. The lower tail for $T_{\text {MAX }}$ in North America in JJA is too low and the upper tail too high in ACCESS1.3b. Generally, the lower tail of $T_{\mathrm{MIN}}$ is reproduced better than the upper tail, whereas the upper tail in $T_{\mathrm{MAX}}$ is often reproduced better than the lower tail.

\section{Discussion}

The driver of temperatures at the Earth's surface is the surface radiation balance, but different components of the radiation balance are associated with $T_{\mathrm{MIN}}$ and $T_{\mathrm{MAX}}$. The daily minimum temperature, which normally occurs just before sunrise, is mainly determined by longwave radiation (LW) because there is no shortwave (SW) radiation during 
a) Temporal Correlation ( $\mathrm{T}_{\text {MIN }}$ bias, $\mathrm{LW}_{\text {IN }}$ bias) $[-]$

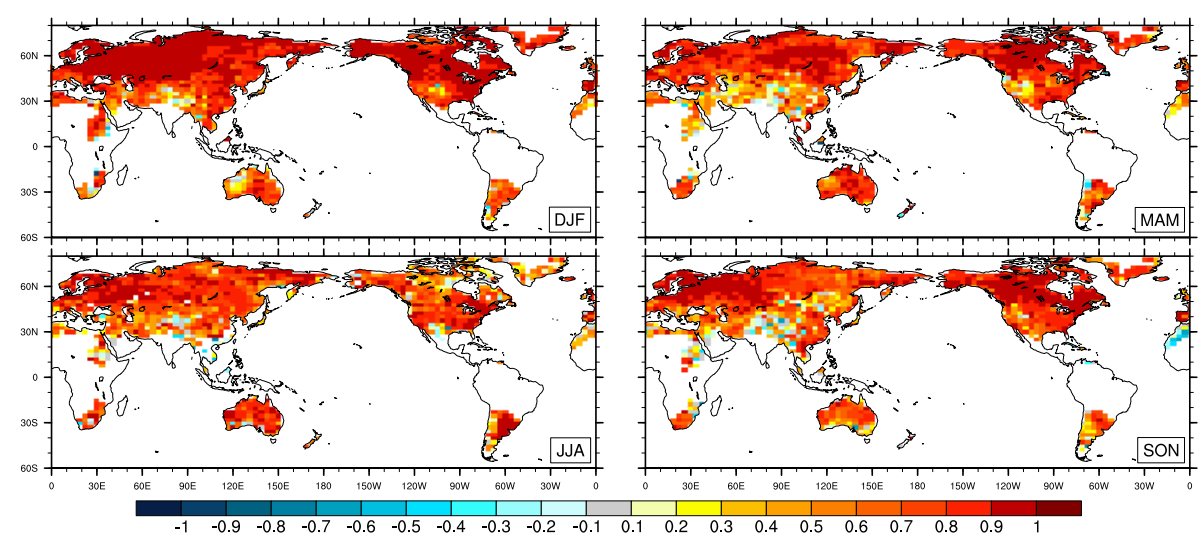

b) Temporal Correlation ( $\mathrm{T}_{\mathrm{MAX}}$ bias, $\mathrm{SW}_{\mathrm{NET}}$ bias) [-]

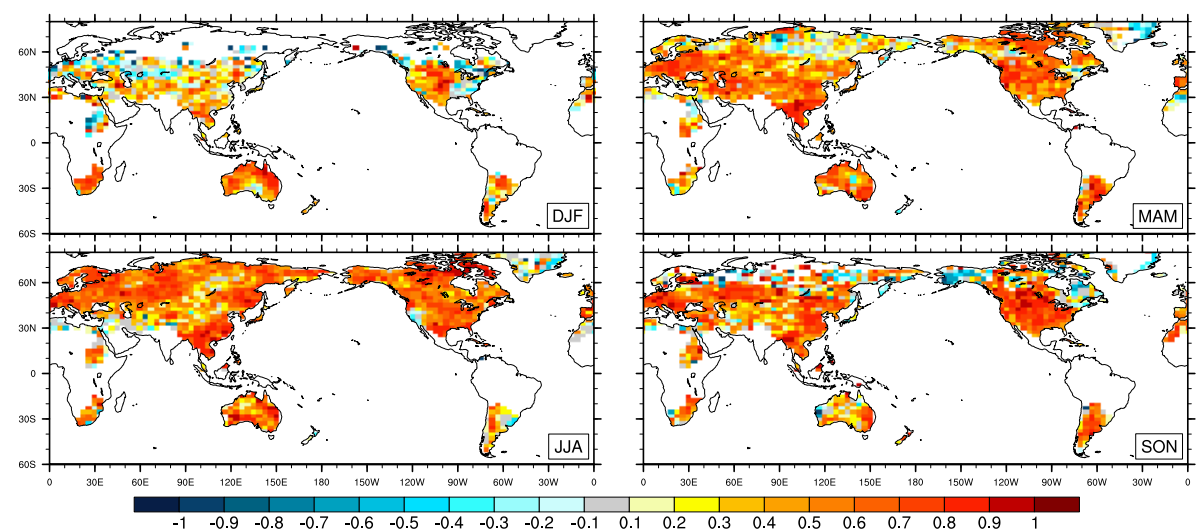

Fig. 12. Correlations for biases between ACCESS1.3b and observations in $T_{\mathrm{MIN}}$ and $\mathrm{LW}_{\mathrm{IN}}(\mathbf{a})$, and $T_{\mathrm{MAX}}$ and $\mathrm{SW}$ NET (b) in all seasons. Biases smaller than $\pm 1^{\circ} \mathrm{C}$ and $\pm 10 \mathrm{~W} \mathrm{~m}^{-2}$ were masked before the calculation of the correlations and are represented by white.

the night. The magnitude of incoming long waves $\left(\mathrm{LW}_{\mathrm{IN}}\right)$ depends on sky temperature and emissivity and is affected by cloud cover and humidity, while outgoing LW depends on the emissivity and temperature of the Earth's surface. Maximum temperatures during the day are dependent on the incoming solar radiation (SW) and modulated by cloud cover and aerosols. Surface temperatures are also affected by the surface albedo, availability of soil moisture for evapotranspiration and stability conditions of the atmosphere. We examined the biases in net longwave ( $\left.\mathrm{LW}_{\mathrm{NET}}\right)$ and net shortwave $\left(\mathrm{SW}_{\mathrm{NET}}\right)$ from ACCESS1.3b to explain the biases in temperature. The CERES satellite product is used to estimate the biases in the radiative fluxes, which has a well-defined level of accuracy. When compared to CERES, ACCESS generally has an excess amount of SW absorbed at the surface (Fig. 11a) in all seasons. In the Northern Hemisphere this is small in DJF and largest in JJA, where the bias exceeds $50 \mathrm{~W} \mathrm{~m}^{-2}$ over Europe and North America. There are other regions with biases exceeding $50 \mathrm{~W} \mathrm{~m}^{-2}$, including central Africa, India and the Amazon delta (Fig. 11a). The high bias in $\mathrm{SW}_{\text {NET }}$ (Fig. 11a) is likely associated with a low cloud bias enabling excessive incoming SW. This is evident in JJA over India, where the Indian monsoon is severely underpredicted; see Fig. 3 . The bias in $\mathrm{LW}_{\mathrm{NET}}$ is generally negative (Fig. 11b), especially in the arid and semi-arid areas, pointing to either outgoing LW being overestimated or incoming LW being underestimated. Outgoing LW radiation is directly proportional to the surface temperature to the 4 th power. In areas with positive biases in $T_{\mathrm{MIN}}$ and $T_{\mathrm{MAX}}$, ACCESS overestimates outgoing LW, which could explain the negative bias in $\mathrm{LW}_{\mathrm{NET}}$ radiation in central Eurasia and North America in JJA. Overall, the largest errors in $\mathrm{SW}_{\mathrm{NET}}$ are in JJA in the Northern Hemisphere and India as well as the Amazon delta in SON. While the largest biases in $\mathrm{LW}_{\mathrm{NET}}$ occur in warm seasons in the arid and semi-arid areas of North Africa, central Eurasia, the Middle East, India, North America and Australia, the biases in LW and SW lead to an overall overestimation of total net radiation in the Northern Hemisphere spring and summer and most of the tropics (not shown).

We calculate temporal correlations between the biases in $T_{\mathrm{MIN}}, T_{\mathrm{MAX}}$ and radiation per season at each longitude, latitude (using the NCAR Command Language "NCL" function "escorc") when biases are larger than $\pm 1{ }^{\circ} \mathrm{C}$ or $\pm 10 \mathrm{~W} \mathrm{~m}^{-2}$ respectively. The bias in $T_{\mathrm{MIN}}$ correlates strongly with the 
a) LH bias: ACCESS-GLEAM [Wm $\left.{ }^{-2}\right]$

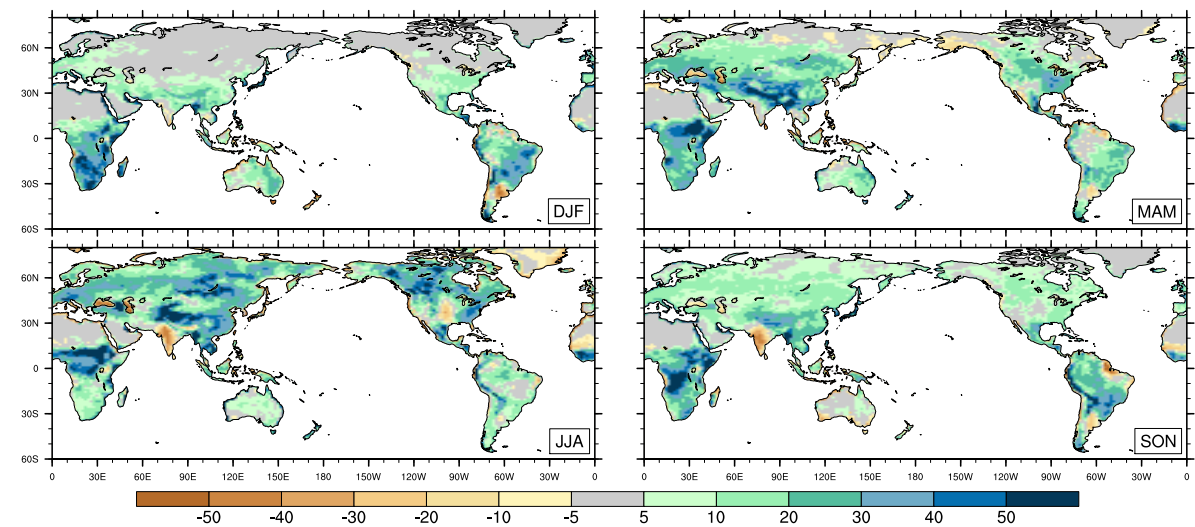

b)

LH bias ACCESS-LandFluxEVAL [ $\mathrm{Wm}^{-2}$ ]

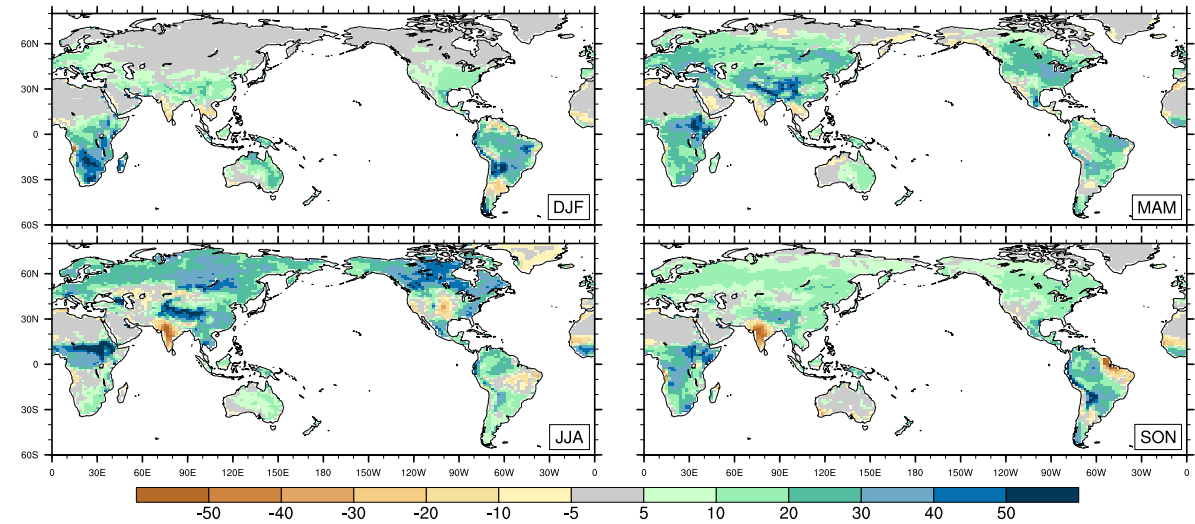

c)

Temporal Correlation ( $\mathrm{T}_{\text {MAX }}$ bias, LHbias) [-]

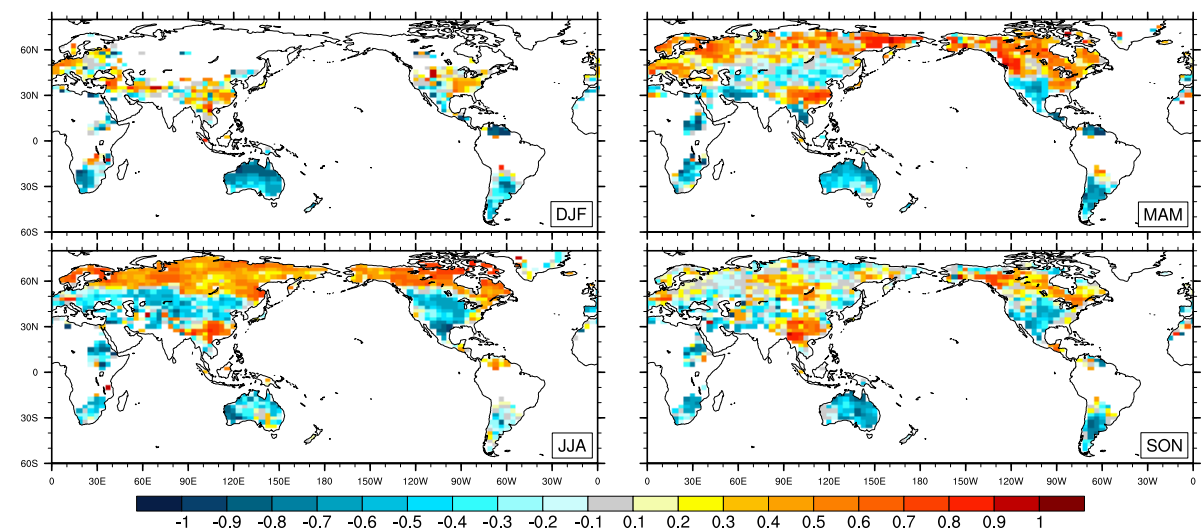

Fig. 13. Biases between ACCESS1.3b and GLEAM data (a) respectively, LandFlux-EVAL (b) for latent heat flux and correlations for biases between ACCESS1.3b and observations in $T_{\mathrm{MAX}}$ and LH (c) in all seasons. The considered time periods are the overlapping time periods between model run and observations, 1984-2007 (a) and 1985-2005 (b, c). Biases smaller than $\pm 1^{\circ} \mathrm{C}$ and $\pm 10 \mathrm{~W} \mathrm{~m}^{-2}$ were masked before the calculation of the correlations and are represented by white.

bias in incoming LW (Fig. 12a). This provides further evidence to associate this temperature bias with problems in the ACCESS1.3b simulated cloud cover. Franklin et al. (2013b) evaluated cloud fraction in ACCESS1.3 in detail. They found that clouds are represented reasonably but found differences in the horizontal distribution. These include a tendency towards too few clouds throughout the subtropics and trade wind regions, an underestimation of up to $25 \%$ in DJF over Russia as well as an underestimation of $30 \%$ in JJA over North America. The bias in $T_{\mathrm{MAX}}$ correlates with the bias 
in $\mathrm{SW}_{\mathrm{NET}}$, but the correlation is weaker than for $T_{\mathrm{MIN}}$ and $\mathrm{LW}_{\mathrm{IN}}$. For example, regions with large negative biases in

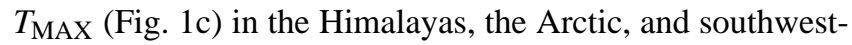
ern South America, which are persistent in all seasons, do not always correspond to a negative bias in $\mathrm{SW}_{\mathrm{NET}}$ (Fig. 11a). In the Northern Hemisphere summer, correlations between $\mathrm{SW}_{\mathrm{NET}}$ biases and $T_{\mathrm{MAX}}$ biases are strong (Fig. 12b) and usually exceed $\sim 0.8$. However, in SON and MAM, and in particular in DJF in the Northern Hemisphere, the correlation between $\mathrm{SW}_{\mathrm{NET}}$ biases and $T_{\mathrm{MAX}}$ becomes weaker and even negative at some grid points (Fig. 12b). The weaker correlations between $\mathrm{SW}_{\mathrm{NET}}$ and biases in $T_{\mathrm{MAX}}$ (Fig. 12b) point to factors other than atmospheric processes playing a role, and these are likely to be linked to land processes.

ACCESS $1.3 \mathrm{~b}$ is generally lacking in its capacity to capture $T_{\text {MAX }}$. This was apparent in Fig. 1c for $T_{\text {MAX }}$ and Fig. 6 for DTR. Reflecting on Figs. 9 and 10, the simulation of $T_{\mathrm{MAX}}$ was shifted to the left in the ACCESS1.3b model in both DJF and JJA in all four regions. It is noteworthy that the largest biases tended to be at the lower tail of the PDF for $T_{\mathrm{MAX}}$ (only in Europe and Asia in DJF was this not true). The most straightforward explanation for this is linked with evapotranspiration. For instance, Watterson (1997) found close spatial correlations between DTR and $\mathrm{SW}_{\mathrm{NET}}$ minus the evaporative and sensible fluxes, or $\mathrm{LW}_{\mathrm{NET}}$. Examining how well a land-surface model simulates evapotranspiration is challenging because a bias in this quantity can result from poor forcing (rainfall, SW and LW), poor surface states (soil moisture) or poor parameterisation of the relationship between the states and the fluxes. It is also challenging because there are considerable uncertainties in estimates of evapotranspiration from observation-based products. We use GLEAM (see Sect. 2.5), recognising that this product is a model-based estimate of evapotranspiration and that there are likely significant uncertainties associated with the estimates. To decrease these uncertainties we use a second ET product, the multidata synthesis LandFlux-EVAL.

Figure 13a shows the simulation of evapotranspiration in ACCESS1.3b compared with GLEAM, Fig. 13b shows the same for LandFlux-EVAL. There is a systematic bias in simulated evapotranspiration, commonly reaching $30 \mathrm{~W} \mathrm{~m}^{-2}$ and regionally exceeding $50 \mathrm{~W} \mathrm{~m}^{-2}$. In almost all cases, ACCESS1.3b simulates excess evapotranspiration. This is in contrast to Zhang et al. (2013), who found an underestimation of ET in the tropics in offline CABLE2.0 runs. There are, however, some important exceptions; there is too little ET over the Indian subcontinent in JJA and SON linked with the failure of the monsoon in this model. There is also a lack of evapotranspiration over parts of North America, despite the excess SW, in JJA. However, the pattern of excess evapotranspiration shown in Fig. 13a and b is large-scale and systematic. The patterns of the evapotranspiration biases are dissimilar to the $\mathrm{LW}_{\mathrm{NET}}$ biases (Fig. 11b) and are weakly linked to the biases in $\mathrm{SW}_{\mathrm{NET}}$ (Fig. 11a). The largest positive ET biases occur in densely forested areas (e.g. tropics) and in the Northern Hemisphere in summer. As shown in Fig. 1c, most of the biases in $T_{\mathrm{MAX}}$ are small, or negative except over the mid-latitudes of the Northern Hemisphere in JJA, which are closely linked to the negative rainfall bias in the model (Fig. 3c). This general low bias in $T_{\text {MAX }}$ could be explained by the excessive evapotranspiration, which has been found in other climate models as well (Mueller and Seneviratne, 2014). Figure 13c shows the temporal correlation (calculated as for temperature and radiation using NCL's "escorc") between biases in $T_{\mathrm{MAX}}$ and biases in evapotranspiration (or latent heat flux, $\mathrm{LH}$, in $\left.\mathrm{Wm}^{-2}\right)$. Small biases $\left(< \pm 1{ }^{\circ} \mathrm{C}\right.$ for $T_{\text {MAX }}$ and $< \pm 10 \mathrm{~W} \mathrm{~m}^{-2}$ for $\mathrm{LH}$ ) are masked to focus on the correlation of significant biases. We expect a negative correlation in areas where either ET is too low and $T_{\mathrm{MAX}}$ is too high or ET is too high and $T_{\mathrm{MAX}}$ is too low. There are many regions where the biases in $\mathrm{LH}$ and $T_{\mathrm{MAX}}$ are negatively correlated. These include regions over the mid-latitudes of the Northern Hemisphere in JJA, Eurasia in SON and the Southern Hemisphere in DJF and JJA. There are also large areas where the correlation is positive, including parts of the midlatitudes of the Northern Hemisphere in SON, high latitudes in MAM and southeast Asia in MAM, JJA and SON. Unfortunately, using $\mathrm{LH}$ to explain biases in $T_{\mathrm{MAX}}$ is limited by major gaps in $T_{\mathrm{MAX}}$ observations. Despite this, the regions where the clearest negative correlations are found, and the seasons they occur within, are not unexpected. Areas with negative correlations correspond to areas where ET is limited by soil moisture availability, areas where the correlation between $T_{\mathrm{MAX}}$ and ET biases is positive relate to areas where ET is limited by radiation/temperature (see Seneviratne et al., 2010; Jung et al., 2010; Wang and Dickinson, 2012). In regions where ET is limited by soil moisture, a high influence from the land surface on temperature is expected due to strong land-atmosphere coupling (e.g. Seneviratne et al., 2010; Mueller and Seneviratne, 2012). These tend to be transitional regions between wet and dry climates during the summer season in both hemispheres. This link between biases and coupling is an area we will pursue in the future.

One question might be how the ACCESS1.3b simulation of the ETCCDI indices compares with other models. Our use of AMIP makes a direct comparison with other models unfeasible. However, Sillmann et al. (2013) have provided an evaluation of climate extreme indices from CMIP-5 models for the present climate. In addition to HadEX2, they included four reanalysis data sets in their analysis. Some of the reanalysis also shows large biases to the observations, partly due to different computational approaches when calculating indices from daily grid-point averages in comparison to grids of station extremes (Donat et al., 2014). Therefore, biases between reanalyses/model output and observations are expected to some degree because of scaling effects. Sillmann et al. (2013) concluded that CMIP-5 models are generally able to simulate climate extremes and their trend patterns in comparison to HadEX2. The percentile indices TN10p, 
TX10, TN90p and TX90p compare very well with CMIP5 since they are calculated relative to their specific PDF, thus insensitive to biases in absolute temperature values. Sillmann et al. (2013) also found that models and reanalyses disagree with HadEX2 for DTR. HadEX2 shows much larger values for DTR than the median of the analysed CMIP-5 models and most reanalyses. The question might arise if the comparison of the models to HadEX2 is fair for DTR. As mentioned in Sect. 2.5, extreme indices derived from model output are expected to be less intense than those derived from station observations. The spatial-scale mismatch between the model and HadEX2 probably explains a small part of the bias. However, the spatial mismatch between models and observations plays less of a role for indices based on monthly averages such as DTR. HadGHCND $T_{\mathrm{MAX}}$ and $T_{\mathrm{MIN}}$ seasonal averages also suggest an underestimation of the DTR. In addition, Lewis and Karoly (2013) also found deficiencies in the CMIP-5 models in simulating trends in DTR. Hence, the underestimation of DTR is a common problem in many climate models although it remains possible that the model-derived DTR is not directly comparable with the observed derived value. Rx1day was not considered in Sillmann et al. (2013). For Rx5day, ACCESS1.3b's global mean is higher than the median of the CMIP-5 ensemble investigated by Sillmann et al. (2013), CWD is at the lower end of the CMIP-5 models and CDD is also lower than the CMIP-5 median. ACCESS1.0 was among the models that reproduces most temperature and precipitation indices reasonably well in Sillmann et al. (2013). Therefore, overall, ACCESS1.3b performs comparably to other CMIP-5 models for ETCCDI, with some indices simulated particularly well, and others in a more limited way.

\section{Conclusions}

To provide a benchmark for how well the ACCESS1.3b climate model simulates extremes, we undertook an AMIPstyle simulation involving simulations over the 1950-2012 period with prescribed sea surface temperatures and sea ice concentration. Our goal was to identify strengths and weaknesses in the ACCESS1.3b modelling system to provide a basis for experiments and model developments to resolve these weaknesses. Our analysis is founded on the capacity of the model to simulate daily $T_{\mathrm{MAX}}, T_{\mathrm{MIN}}$ and precipitation. From these three variables we calculated climate extremes derived by the Expert Team on Climate Change Detection and Indices (ETCCDI). This work builds on earlier analyses of the mean climate of the ACCESS1.3 model, that included CABLE1.8 rather than CABLE2.0 by Kowalczyk et al. (2013) and Bi et al. (2013). These analyses showed that ACCESS1.3 captured the large-scale mean temperature and precipitation well, and compared favourably with other climate models in CMIP-5. Our analysis highlighted a large $\left(2-6^{\circ} \mathrm{C}\right)$ cold bias in the simulation of $T_{\mathrm{MAX}}$ in all seasons and in all regions except North America. We also showed a large positive bias $\left(1-5^{\circ} \mathrm{C}\right)$ in $T_{\mathrm{MIN}}$ in all seasons and in all regions. As a consequence, ACCESS1.3b fails to represent the diurnal temperature range well in comparison with the HadEX2 data. However, the model captures patterns in, and trends in, indices for cool nights (TN10p) and cold days (TX10p) extremely well, although there is an overestimation in the change in both indices between $\sim 1975$ and 2010. Warm nights (TN90p) and warm days (TX90p) are also captured well. ACCESS1.3b simulates rainfall indices quite variably. Rainfall intensity (Rx1day) is simulated reasonably well, but consecutive wet days are badly overestimated and consecutive dry days are badly underestimated in the model. The biases in temperature related indices are very likely associated with a large positive bias in net shortwave radiation (Fig. 12a) and a large negative bias in net longwave radiation (Fig. 12b). Some of the precipitation biases are related to the common "drizzle" problem. Our results highlight challenges in simulating climate extremes in climate models, a result previously identified (Kiktev et al., 2003; Kharin et al., 2013; Sillmann et al., 2013). However, our results provide a benchmark from which we will now examine how land processes can be improved to capture these extremes. There are some clear ways forward for improving the model. Some of the biases are likely linked with a bias in simulating evapotranspiration and this will be a priority to resolve. For example, application of the GLACE methodology (Koster et al., 2006) could be used to quantify the degree of land-atmosphere coupling in ACCESS. Other biases might be linked with albedo, especially the correct parameterisation of snow albedo, which is a common challenge in land-surface models. It will be more challenging to identify how to improve the cloud climatology, but by identifying these biases, and the impact these have on extreme indices, we provide a clear statement of the state of ACCESS1.3b and a benchmark from which the model can be improved.

Acknowledgements. We thank Dan Copsey from the UK Meteorological Office for producing ancillary files enabling our simulation of the AMIP period. We also thank Scott Wales for technical support and Lauren Stevens and Sophie Lewis for help with ACCESS. Ian Watterson provided valuable comment on a draft of this paper. This work was supported by the Australian Research Council Centre of Excellence for Climate System Science grant CE110001028. The computational modelling was supported by the NCI National Facility at the ANU, Australia. The GPCP combined precipitation data were developed and computed by the NASA/Goddard Space Flight Center's Laboratory for Atmospheres as a contribution to the GEWEX Global Precipitation Climatology Project. GPCP data provided by the NOAA/OAR/ESRL PSD, Boulder, Colorado, USA, from their Web site at http://www.esrl.noaa.gov/psd/. NCL (2013) and R (2013) were used to draw the figures. We thank the referees, V. Brovkin and J. Mao, for their valuable comments to improve this manuscript.

Edited by: A. Kerkweg 


\section{References}

Abramowitz, G., Leuning, R., Clark, M., and Pitman, A.: Evaluating the Performance of Land Surface Models, J. Climate, 21, 54685481, doi:10.1029/2005JD006290, 2008.

Adler, R., Huffmann, G., Chang, A., Ferraro, R., Xie, P.-P., Janowiak, J., Rudolf, B., Schneider, U., Curtis, S., Bolvin, D., Gruber, A., Susskind, J., Arkin, P., and Nelkin, E.: The Version-2 Global Precipitation Climatology Project (GPCP) Monthly Precipitation Analysis (1979-Present), J. Hydrometeorol., 4, 11471167, 2003.

Alexander, L. V., Zhang, X., Peterson, T. C., Caesar, J., Gleason, B., Klein Tank, A. M. G., Haylock, M., Collins, D., Trewin, B., Rahimzadeh, F., Tagipour, A., Rupa Kumar, K., Revadekar, J., Griffiths, G., Vincent, L., Stephenson, D. B., Burn, J., Aguilar, E., Brunet, M., Taylor, M., New, M., Zhai, P., Rusticucci, M., and Vazquez-Aguirre, J. L.: Global observed changes in daily climate extremes of temperature and precipitation, J. Geophys. Res., 111, D05109, doi:10.1029/2005JD006290, 2006.

Arblaster, J. M. and Alexander, L. V.: The impact of the El NiñoSouthern Oscillation on maximum temperature extremes, Geophys. Res. Lett., 39, L20702, doi:10.1029/2012GL053409, 2012.

Bi, D., Dix, M., Marsland, S. J., Farrell, S. O., Rashid, H. A., Uotila, P., Hirst, A. C., Kowalczyk, E., Golebiewski, M., Sullivan, A., Yan, H., Hannah, N., Franklin, C., Sun, Z., Vohralik, P., Watterson, I., Zhou, X., Fiedler, R., Collier, M., Ma, Y., Noonan, J., Stevens, L., Uhe, P., Zhu, H., Griffies, S. M., Hill, R., Harris, C., and Puri, K.: The ACCESS coupled model: Description, control climate and evaluation, Aust. Meteorol. Oceanogr. J., 63, 9-32, 2013.

Caesar, J., Alexander, L., and Vose, R.: Large-scale changes in observed daily maximum and minimum temperatures: Creation and analysis of a new gridded data set, J. Geophys. Res., 111, D05101, doi:10.1029/2005JD006280, 2006.

Ciais, P., Reichstein, M., Viovy, N., Granier, A., Ogée, J., Allard, V., Aubinet, M., Buchmann, N., Bernhofer, C., Carrara, A., Chevallier, F., De Noblet, N., Friend, A. D., Friedlingstein, P., Grünwald, T., Heinesch, B., Keronen, P., Knohl, A., Krinner, G., Loustau, D., Manca, G., Matteucci, G., Miglietta, F., Ourcival, J. M., Papale, D., Pilegaard, K., Rambal, S., Seufert, G., Soussana, J. F., Sanz, M. J., Schulze, E. D., Vesala, T., and Valentini, R.: Europewide reduction in primary productivity caused by the heat and drought in 2003, Nature, 437, 529-533, 2005.

Coumou, D. and Rahmstorf, S.: A decade of weather extremes, Nat. Clim. Chang., 2, 491-496, doi:10.1038/nclimate1452, 2012.

Dai, A.: Precipitation Characteristics in Eighteen Coupled Climate Models, J. Climate, 19, 4605-4630, doi:10.1175/JCLI3884.1, 2006.

Davies, T., Cullen, M. J. P., Malcolm, A. J., Mawson, M. H., Staniforth, A., White, A. A., and Wood, N.: A new dynamical core for the Met Office's global and regional modelling of the atmosphere, Q. J. R. Meteorol. Soc., 131, 1759-1782, doi:10.1256/qj.04.101, 2005.

de Noblet-Ducoudré, N., Boisier, J.-P., Pitman, A., Bonan, G. B., Brovkin, V., Cruz, F., Delire, C., Gayler, V., van den Hurk, B. J. J. M., Lawrence, P. J., van der Molen, M. K., Müller, C., Reick, C. H., Strengers, B. J., and Voldoire, A.: Determining Robust Impacts of Land-Use-Induced Land Cover Changes on
Surface Climate over North America and Eurasia: Results from the First Set of LUCID Experiments, J. Climate, 25, 3261-3281, doi:10.1175/JCLI-D-11-00338.1, 2012.

Donat, M. G. and Alexander, L. V.: The shifting probability distribution of global daytime and night-time temperatures, Geophys. Res. Lett., 39, L14707, doi:10.1029/2012GL052459, 2012.

Donat, M., Alexander, L., Yang, H., Durre, I., Vose, R., and Caesar, J.: Global land-based datasets for monitoring climatic extremes, Bull. Am. Meteorol. Soc., 94, 997-1006, doi:10.1175/BAMS-D12-00109, 2013a.

Donat, M. G., Alexander, L. V., Yang, H., Durre, I., Vose, R., Dunn, R. J. H., Willett, K. M., Aguilar, E., Brunet, M., Caesar, J., Hewitson, B., Jack, C., Klein Tank, A. M. G., Kruger, A. C., Marengo, J., Peterson, T. C., Renom, M., Oria Rojas, C., Rusticucci, M., Salinger, J., Elrayah, A. S., Sekele, S. S., Srivastava, A. K., Trewin, B., Villarroel, C., Vincent, L. A., Zhai, P., Zhang, X., and Kitching, S.: Updated analyses of temperature and precipitation extreme indices since the beginning of the twentieth century: The HadEX2 dataset, J. Geophys. Res. Atmos., 118, 2098-2118, doi:10.1002/jgrd.50150, 2013b.

Donat, M. G., Sillmann, J., Wild, S., Alexander, L., Lippmann, T., and Zwiers, F. W.: Consistency of temperature and precipitation extremes across various global gridded in situ and reanalysis datasets, J. Climate, doi:10.1175/JCLI-D-13-00405.1, in press, 2014.

Easterling, D. R.: Climate Extremes: Observations, Modeling, and Impacts, Science, 289, 2068-2074, 2000.

Edwards, J. and Slingo, A.: Studies with a flexible new radiation code. I: Choosing a configuration for a large-scale model, Q. J. R. Meteorol. Soc., 122, 689-719, 1996.

Ek, M. B. and Holtslag, A. A. M.: Influence of Soil Moisture on Boundary Layer Cloud Development, J. Hydrometeorol., 5, 8699, 2004.

Findell, K. L. and Eltahir, E. A. B.: Atmospheric Controls on Soil Moisture - Boundary Layer Interactions, Part II : Feedbacks within the Continental United States, J. Hydrometeorol., 4, 570583, 2003.

Fischer, E. M., Seneviratne, S. I., Lüthi, D., and Schär, C.: Contribution of land-atmosphere coupling to recent European summer heat waves, Geophys. Res. Lett., 34, L06707, doi:10.1029/2006GL029068, 2007.

Franklin, C. N., Sun, Z., Bi, D., Dix, M., Yan, H., and Bodas-Salcedo, A.: Evaluation of clouds in ACCESS using the satellite simulator package COSP: Regime-sorted tropical cloud properties, J. Geophys. Res. Atmos., 118, 6663-6679, doi:10.1002/jgrd.50496, 2013a.

Franklin, C. N., Sun, Z., Bi, D., Dix, M., Yan, H., and BodasSalcedo, A.: Evaluation of clouds in ACCESS using the satellite simulator package COSP: Global, seasonal, and regional cloud properties, J. Geophys. Res. Atmos., 118, 732-748, doi:10.1029/2012JD018469, 2013b.

Gates, W. L.: AMIP: The Atmospheric Model Intercomparison Project, Bull. Am. Meteorol. Soc., 73, 1962-1970, 1992.

GLOBE Task Team and others: The Global Land One-kilometer Base Elevation (GLOBE) Digital Elevation Model, National Oceanic and Atmospheric Administration, National Geophysical Data Center, 325 Broadway, Boulder, COlorado 80305-3328, U.S.A., version 1. edn., available at: http://www.ngdc.noaa.gov/ mgg/topo/globe.html, 1999. 
Gregory, D. and Rowntree, P.: A Mass Flux Convection Scheme with Representation of Cloud Ensemble Characteristics and Stability-Dependent Closure, Mon. Weather Rev., 118, 14831506, 1990.

Hewitt, H. T., Copsey, D., Culverwell, I. D., Harris, C. M., Hill, R. S. R., Keen, A. B., McLaren, A. J., and Hunke, E. C.: Design and implementation of the infrastructure of HadGEM3: the nextgeneration Met Office climate modelling system, Geosci. Model Dev., 4, 223-253, doi:10.doi:10.5194/gmd-4-223-2011, 2011.

Hilton, R. D., Featherstone, W. E., Berry, P. A. M., Johnson, C. P. D., and Kirby, J. F.: Comparison of digital elevation models over Australia and external validation using ERS'1 satellite radar altimetry, Aust. J. Earth Sci., 50, 157-168, 2003.

Hirsch, A. L., Kala, J., Pitman, A. J., Carouge, C., Evans, J. P., Haverd, V., and Mocko, D.: Impact of Land Surface Initialisation Approach on Sub-seasonal Forecast Skill: A Regional Analysis in the Southern Hemisphere, J. Hydrometeorol., 15, 300319, doi:10.1175/JHM-D-13-05.1, 2014.

Hirschi, M., Seneviratne, S. I., Alexandrov, V., Boberg, F., Boroneant, C., Christensen, O. B., Formayer, H., Orlowsky, B., and Stepanek, P.: Observational evidence for soil-moisture impact on hot extremes in southeastern Europe, Nat. Geosci., 4, 17-21, doi:10.1038/ngeo1032, 2010.

IPCC: Managing the Risks of Extreme Events and Disasters to Advance Climate Change Adaptation, Cambridge University Press, Cambridge, doi:10.1017/CBO9781139177245, 2012.

Jaeger, E. B. and Seneviratne, S. I.: Impact of soil moistureatmosphere coupling on European climate extremes and trends in a regional climate model, Clim. Dyn., 36, 1919-1939, 2010.

Jung, M., Reichstein, M., Ciais, P., Seneviratne, S. I., Sheffield, J., Goulden, M. L., Bonan, G., Cescatti, A., Chen, J., de Jeu, R., Dolman, A. J., Eugster, W., Gerten, D., Gianelle, D., Gobron, N., Heinke, J., Kimball, J., Law, B. E., Montagnani, L., Mu, Q., Mueller, B., Oleson, K., Papale, D., Richardson, A. D., Roupsard, O., Running, S., Tomelleri, E., Viovy, N., Weber, U., Williams, C., Wood, E., Zaehle, S., and Zhang, K.: Recent decline in the global land evapotranspiration trend due to limited moisture supply, Nature, 467, 951-4, doi:10.1038/nature09396, 2010.

Kato, S., Loeb, N. G., Rose, F. G., Doelling, D. R., Rutan, D. A., Caldwell, T. E., Yu, L., and Weller, R. A.: Surface Irradiances Consistent with CERES-Derived Top-of-Atmosphere Shortwave and Longwave Irradiances, J. Climate, 26, 27192740, doi:10.1175/JCLI-D-12-00436.1, 2013.

Kharin, V. V., Zwiers, F. W., Zhang, X., and Wehner, M.: Changes in temperature and precipitation extremes in the CMIP5 ensemble, Clim. Change, 119, 345-357, 2013.

Kiktev, D., Sexton, D. M. H., Alexander, L., and Folland, C. K.: Comparison of Modeled and Observed Trends in Indices of Daily Climate Extremes, J. Climate, 16, 3560-3571, 2003.

Koster, R. D., Sud, Y. C., Guo, Z., Dirmeyer, P. A., Bonan, G., Oleson, K. W., Chan, E., Verseghy, D., Cox, P., Davies, H., Kowalczyk, E., Gordon, C. T., Kanae, S., Lawrence, D., Liu, P., Mocko, D., Lu, C.-H., Mitchell, K., Malyshev, S., McAvaney, B., Oki, T., Yamada, T., Pitman, A., Taylor, C. M., Vasic, R., and Xue, Y.: GLACE: The Global Land-Atmosphere Coupling Experiment. Part I: Overview, J. Hydrometeorol., 7, 590-610, doi:10.1175/JHM510.10.1, 2006.
Koster, R. D., Schubert, S. D., and Suarez, M. J.: Analyzing the Concurrence of Meteorological Droughts and Warm Periods, with Implications for the Determination of Evaporative Regime, J. Climate, 22, 3331-3341, doi:10.1175/2008JCLI2718.1, 2009.

Kowalczyk, E. A., Stevens, L., Law, R. M., Dix, M., Wang, Y. P., Harman, I. N., Haynes, K., Srbinovsky, J., Pak, B., and Ziehn, T.: The land surface model component of ACCESS : description and impact on the simulated surface climatology, Aust. Meteorol. Oceanogr. J., 63, 65-82, 2013.

Lewis, S. C. and Karoly, D. J.: Evaluation of historical diurnal temperature range trends in CMIP5 models, J. Climate, 26, 9077 9089, doi:10.1175/JCLI-D-13-00032.1, 2013.

Lock, A. P., Brown, A. R., Bush, M. R., Martin, G. M., and Smith, R. N. B.: A New Boundary Layer Mixing Scheme. Part I: Scheme Description and Single-Column Model Tests, Mon. Weather Rev., 128, 3187-3199, 2000.

Lorenz, R., Jaeger, E. B., and Seneviratne, S. I.: Persistence of heat waves and its link to soil moisture memory, Geophys. Res. Lett., 37, L09703, doi:10.1029/2010GL042764, 2010.

Lorenz, R., Davin, E. L., Lawrence, D. M., Stöckli, R., and Seneviratne, S. I.: How important is vegetation phenology for European climate and heatwaves?, J. Climate, 26, 10077-10100, doi:10.1175/JCLI-D-13-00040.1, 2013.

Ma, L., Zhang, T., Frauenfeld, O. W., Ye, B., Yang, D., and Qin, D.: Evaluation of precipitation from the ERA-40, NCEP-1, and NCEP-2 Reanalyses and CMAP-1, CMAP-2, and GPCP-2 with ground-based measurements in China, J. Geophys. Res., 114, D09105, doi:10.1029/2008JD011178, 2009.

Mao, J., Phipps, S. J., Pitman, A. J., Wang, Y. P., Abramowitz, G., and Pak, B.: The CSIRO Mk3L climate system model v1.0 coupled to the CABLE land surface scheme v1.4b: evaluation of the control climatology, Geosci. Model Dev., 4, 1115-1131, doi:10.doi:10.5194/gmd-4-1115-2011, 2011.

Martin, G. M., Ringer, M. A., Pope, V. D., Jones, A., Dearden, C., and Hinton, T. J.: The Physical Properties of the Atmosphere in the New Hadley Centre Global Environmental Model (HadGEM1). Part I: Model Description and Global Climatology, J. Climate, 19, 1274-1301, doi:10.1175/JCLI3636.1, 2006.

Miralles, D. G., Holmes, T. R. H., De Jeu, R. A. M., Gash, J. H., Meesters, A. G. C. A., and Dolman, A. J.: Global land-surface evaporation estimated from satellite-based observations, Hydrol. Earth Syst. Sci., 15, 453-469, doi:10.doi:10.5194/hess-15-4532011, 2011.

Mueller, B. and Seneviratne, S. I.: Hot days induced by precipitation deficits at the global scale, Proc. Natl. Acad. Sci. USA, 109, 12398-12403, doi:10.1073/pnas.1204330109, 2012.

Mueller, B. and Seneviratne, S. I.: Systematic land climate and evapotranspiration biases in CMIP5 simulations, Geophys. Res. Lett., 41, doi:10.1002/2013GL058055, online first, 2014.

Mueller, B., Hirschi, M., Jimenez, C., Ciais, P., Dirmeyer, P. A., Dolman, A. J., Fisher, J. B., Jung, M., Ludwig, F., Maignan, F., Miralles, D. G., McCabe, M. F., Reichstein, M., Sheffield, J., Wang, K., Wood, E. F., Zhang, Y., and Seneviratne, S. I.: Benchmark products for land evapotranspiration: LandFluxEVAL multi-data set synthesis, Hydrol. Earth Syst. Sci., 17, 3707-3720, doi:10.doi:10.5194/hess-17-3707-2013, 2013. 
NCL: The NCAR Command Language, doi:10.5065/D6WD3XH5, 2013.

Pall, P., Aina, T., Stone, D. A., Stott, P. A., Nozawa, T., Hilberts, A. G. J., Lohmann, D., and Allen, M. R.: Anthropogenic greenhouse gas contribution to flood risk in England and Wales in autumn 2000, Nature, 470, 382-385, doi:10.1038/nature09762, 2011.

Perkins, S. E., Pitman, A. J., Holbrook, N. J., and McAneney, J.: Evaluation of the AR4 Climate Models' Simulated Daily Maximum Temperature, Minimum Temperature, and Precipitation over Australia Using Probability Density Functions, J. Clim., 20, 4356-4376, doi:10.1175/JCLI4253.1, 2007.

Perkins, S. E., Alexander, L. V., and Nairn, J. R.: Increasing frequency, intensity and duration of observed global heatwaves and warm spells, Geophys. Res. Lett., 39, L20714, doi:10.1029/2012GL053361, 2012.

Pfeifroth, U., Mueller, R., and Ahrens, B.: Evaluation of SatelliteBased and Reanalysis Precipitation Data in the Tropical Pacific, J. Appl. Meteorol. Climatol., 52, 634-644, doi:10.1175/JAMCD-12-049.1, 2013.

Pitman, A. J., de Noblet-Ducoudré, N., Cruz, F. T., Davin, E. L., Bonan, G. B., Brovkin, V., Claussen, M., Delire, C., Ganzeveld, L., Gayler, V., van den Hurk, B. J. J. M., Lawrence, P. J., van der Molen, M. K., Müller, C., Reick, C. H., Seneviratne, S. I., Strengers, B. J., and Voldoire, A.: Uncertainties in climate responses to past land cover change: First results from the LUCID intercomparison study, Geophys. Res. Lett., 36, L14 814, doi:10.1029/2009GL039076, 2009.

Pitman, A. J., de Noblet-Ducoudré, N., Avila, F. B., Alexander, L. V., Boisier, J.-P., Brovkin, V., Delire, C., Cruz, F., Donat, M. G., Gayler, V., van den Hurk, B., Reick, C., and Voldoire, A.: Effects of land cover change on temperature and rainfall extremes in multi-model ensemble simulations, Earth Syst. Dynam., 3, 213 231, doi:10.doi:10.5194/esd-3-213-2012, 2012.

Priestley, C. H. B. and Taylor, R. J.: On the Assessment of Surface Heat Flux and Evaporation Using Large-Scale Parameters, Mon. Weather Rev., 100, 81-92, 1972.

Puri, K., Dietachmayer, G., Steinle, P., Dix, M., Rikus, L., Logan, L., Naughton, M., Tingwell, C., Xiao, Y., Barras, V., Bermous, I., Bowen, R., Deschamps, L., Franklin, C., Fraser, J., Glowacki, T., Harris, B., Lee, J., Le, T., Roff, G., Sulaiman, A., Sims, H., Sun, X., Sun, Z., Zhu, H., Chattopadhyay, M., and Engel, C.: Implementation of the initial ACCESS numerical weather prediction system, Aust. Meteorol. Oceanogr. J., 63, 265-284, 2013.

R core Team: R: A Language and Environment for Statistical Computing, available at: http://www.r-project.org, 2013.

Seneviratne, S. I., Lüthi, D., Litschi, M., and Schär, C.: Landatmosphere coupling and climate change in Europe, Nature, 443, 205-209, 2006.

Seneviratne, S. I., Corti, T., Davin, E. L., Hirschi, M., Jaeger, E. B., Lehner, I., Orlowsky, B., and Teuling, A. J.: Investigating soil moisture-climate interactions in a changing climate: A review, Earth-Science Rev., 99, 125-161, doi:10.1016/j.earscirev.2010.02.004, 2010.

Seneviratne, S. I., Nicholls, N., Easterling, D. R., Goodess, C. M., Kanae, S., Kossin, J., Luo, Y., Marengo, J., McInnes, K., Rahimi, M., Reichstein, M., Sorteberg, A., Vera, C., and Zhang, X.: Changes in Climate Extremes and their Impacts on the Natural Physical Environment, in: Manag. Risks Extrem. Events Disasters to Adv. Clim. Chang. Adapt, edited by: Field, C. B., Barros,
V., Stock, T. F., Qin, D., Dokken, D. J., Ebi, K. L., Mastrandrea, M. D., Mach, K. J., Plattner, G.-K., Allen, S. K., Tignor, M., and Midgley, P. M., 109-230, Cambridge University Press, Cambridge, UK, and New York, NY, USA, 2012.

Shonk, J. K. P. and Hogan, R. J.: Tripleclouds: An Efficient Method for Representing Horizontal Cloud Inhomogeneity in 1D Radiation Schemes by Using Three Regions at Each Height, J. Climate, 21, 2352-2370, doi:10.1175/2007JCLI1940.1, 2008.

Sillmann, J., Kharin, V. V., Zhang, X., Zwiers, F. W., and Bronaugh, D.: Climate extremes indices in the CMIP5 multimodel ensemble: Part 1. Model evaluation in the present climate, J. Geophys. Res. Atmos., 118, 1716-1733, doi:10.1002/jgrd.50203, 2013.

Stéfanon, M., Drobinski, P., D'Andrea, F., and de NobletDucoudré, N.: Effects of interactive vegetation phenology on the 2003 summer heat waves, J. Geophys. Res., 117, D24103, doi:10.1029/2012JD018187, 2012.

Taylor, C. M. and Ellis, R. J.: Satellite detection of soil moisture impacts on convection at the mesoscale, Geophys. Res. Lett., 33, 11-14, doi:10.1029/2005GL025252, 2006.

Taylor, K. E., Williamson, D., and Zwiers, F.: The Sea Surface Temperature and Sea-Ice Cconcentration Boundary Conditions For AMIP II Simulations, Tech. rep., PCMDI Rep. No. 60, 2000.

Tebaldi, C., Hayhoe, K., Arblaster, J. M., and Meehl, G. A.: Going to the Extremes, Clim. Change, 79, 185-211, doi:10.1007/s10584-006-9051-4, 2006.

Wang, K. and Dickinson, R. E.: A Review of Global Terrestrial Evapotranspiration: Observation, Modeling, Climatology, and Climatic Variability, Rev. Geophys., 50, RG2005, doi:10.1029/2011RG000373.1, 2012.

Wang, Y. and Leuning, R.: A two-leaf model for canopy conductance, photosynthesis and partitioning of available energy I: Model description and comparison with a multi-layered model, Agric. For. Meteorol., 91, 89-111, doi:10.1016/S01681923(98)00061-6, 1998.

Wang, Y. P., Kowalczyk, E., Leuning, R., Abramowitz, G., Raupach, M. R., Pak, B., van Gorsel, E., and Luhar, A.: Diagnosing errors in a land surface model (CABLE) in the time and frequency domains, J. Geophys. Res., 116, G01034, doi:10.1029/2010JG001385, 2011.

Watterson, I. G.: The diurnal cycle of surface air temperature in simulated present and doubled CO 2 climates, Clim. Dynam., 13, 533-545, doi:10.1007/s003820050181, 1997.

Wilson, D. R., Bushell, A. C., Kerr-Munslow, A. M., Price, J. D., and Morcrette, C. J.: PC2: A prognostic cloud fraction and condensation scheme. I: Scheme description, Q. J. R. Meteorol. Soc., 134, 2093-2107, doi:10.1002/qj.333, 2008.

Zaitchik, B. F., Macalady, A. K., Bonneau, L. R., and Smith, R. B.: Europe's 2003 heat wave: a satellite view of impacts and land-atmosphere feedbacks, Int. J. Climatol., 26, 743-769, doi:10.1002/joc.1280, 2006.

Zhang, H., Pak, B., Wang, Y. P., Zhou, X., Zhang, Y., and Zhang, L.: Evaluating Surface Water Cycle Simulated by the Australian Community Land Surface Model (CABLE) across Different Spatial and Temporal Domains, J. Hydrometeorol., 14, 1119-1138, doi:10.1175/JHM-D-12-0123.1, 2013. 
Zhang, X., Alexander, L., Hegerl, G. C., Jones, P., Tank, A. K., Peterson, T. C., Trewin, B., and Zwiers, F. W.: Indices for monitoring changes in extremes based on daily temperature and precipitation data, Wiley Interdiscip. Rev. Clim. Chang., 2, 851-870, doi:10.1002/wcc.147, 2011.
Zwiers, F. W. and von Storch, H.: Taking Serial Correlation into Account in Tests of the Mean, J. Climate, 8, 336-351, 1995. 